\title{
¿Escriben Igual Hombres y Mujeres? Un Estudio de los Generolectos en la Comunicación Mediada por Ordenador
}

\author{
Clàudia Giménez Bedós* \\ Universitat Rovira i Virgili, Tarragona, Spain
}

\begin{abstract}
In the last decades, the Internet has become an information and communication network which reaches a wide audience and which has spread all over the world. Within this communicative context it is of paramount importance to know who hides behind a specific linguistic profile in computer-based communication. In order to establish the features of male and female genderlects, sociolinguistics has been based on oral interactions, but, this traditional classification of male and female language still valid, or should it be updated adapting to this new communication medium? The aim of this project has two sides. On the one hand, we have carried out an analysis just to detect if the traditional characterization of genderlects matches with the linguistic traits which are observed in computer-based communicative exchanges between men and women. On the other hand, we have tried to offer a genderlect characterization which could be useful concerning automatic gender detection tasks.
\end{abstract}

Keywords: Sociolinguistics, genderlects, automatic detection of gender, computermediated communication.

\footnotetext{
* Author's address:

Departament de Filologies Romàniques

Universitat Rovira i Virgili

Av. Catalunya 35, 43002 Tarragona, Spain

E-mail claudia.gimenez@estudiants .urv . cat
} 
Resumen. En las últimas décadas, Internet se ha alzado como una red de información y comunicación que llega a un público muy amplio y que se extiende por todo el mundo. Dentro de este contexto comunicativo es de vital importancia conocer quién se esconde detrás de un determinado perfil lingüístico en la comunicación mediada por ordenador. Para establecer los rasgos de los generolectos femenino y masculino, la sociolingüística se ha basado en las interacciones orales pero, ¿sigue siendo válida la caracterización tradicional del lenguaje de hombres y mujeres, o debería actualizarse adaptándose a este nuevo medio de comunicación? En este trabajo, presentamos un análisis realizado con un doble objetivo: comprobar si la caracterización tradicional de los generolectos coincide con los rasgos lingüísticos que se observan en la comunicación mediada por ordenador en hombres y mujeres; y proporcionar una caracterización generolectal que sea de utilidad en las tareas de detección automática de género.

Palabras clave: Sociolingüística, generolectos, detección automática de género, comunicación mediada por ordenador.

\section{Introducción}

Desde los inicios de la Sociolingüística, se ha venido caracterizando la variación generolectal teniendo en cuenta la interacción oral. Actualmente, el uso generalizado de las redes sociales y otras aplicaciones de mensajería ha hecho que buena parte de las interacciones lingüísticas en las que participamos a diario se incluyan en la denominada "comunicación mediada por ordenador". Ante este hecho, la pregunta que nos planteamos es: ¿sigue siendo válida, en este nuevo contexto comunicativo, la tradicional caracterización del lenguaje de hombres y mujeres?

El desarrollo de nuevas tecnologías ha contribuido a que cualquier persona pueda acceder a esta red de comunicación con tan solo contar con un dispositivo que tenga conexión a Internet. Esta situación posibilita que los usuarios de estas plataformas puedan comunicarse desde el anonimato y con una rapidez incalculable, traspasando fronteras y barreras de todo tipo: geográficas, sociales y/o personales.

En este contexto, la detección automática de autoría ha adquirido mucha importancia, puesto que es necesario disponer de herramientas que sean capaces de detectar quién se esconde tras un determinado perfil. El hecho de conocer quién se esconde detrás de un perfil en la web, y si esa persona es un hombre o una mujer, es una cuestión de interés en varios campos de 
conocimiento, como la lingüística forense, la seguridad o el marketing (Alemán et al. 2014).

Para que la detección de la autoría en general sea posible, es necesario disponer de patrones lingüísticos que caractericen el lenguaje, teniendo en cuenta las distintas variables sociales. De todas ellas, la variable sexo/género es una de las que más interés ha recibido.

Nuestro objetivo principal es ofrecer una descripción lingüística de los generolectos masculino y femenino lo suficientemente precisa para poder ser usada en sistemas de detección automática del género. Para ello, nos proponemos:

- Recoger los rasgos que se han considerado representativos de los generolectos femenino y masculino, teniendo en cuenta bibliografía sociolingüística especializada.

- Comprobar si la caracterización tradicional coincide con los rasgos generolectales que se observan en la comunicación mediada por ordenador, concretamente, en las redes sociales.

- Proporcionar una caracterización generolectal que sirva en las tareas de detección automática de género.

Para realizar nuestro análisis, se han seleccionado un total de 80 hablantes. Los criterios que se han tenido en cuenta para realizar la selección han sido: a) el sexo del informante. Se han seleccionado 40 hombres y 40 mujeres conocidos socialmente; b) la frecuencia de uso de las redes sociales, ya que nos interesan sujetos que tengan una vida activa en Twitter; c) la edad. La franja de edad considerada está entre los 25 y los 75 años, puesto que consideramos importante que la muestra no sea homogénea respecto a esta variable.

La recogida de los datos se ha realizado a través de la herramienta digital Twitter. Se ha seleccionado esta red social y no otra debido a que se trata de una plataforma pública en la que se puede acceder a las publicaciones de cualquier persona que esté registrada en esta. Precisamente por el hecho de ser una red pública, en la que no se necesita una aprobación del usuario para poder seguirlo -como sí ocurre en otras plataformas como Facebook-, muchos usuarios la utilizan para estar al corriente de las publicaciones de personajes públicos. Esta característica nos ha permitido recoger los datos sin necesidad de contar con la aprobación explícita de los individuos seleccionados. Además, Twitter nos ha parecido especialmente interesante porque cuenta con 
una limitación de 140 caracteres para cada publicación, cosa que facilita el análisis. Se han seleccionado aleatoriamente quince tuits de cada uno de los participantes. Nuestro corpus, por tanto, está formado por un total de 1.200 tuits o intervenciones.

El análisis de los datos se ha realizado teniendo en cuenta los siete niveles lingüísticos en los que podemos encontrar diferencias entre hombres y mujeres: ortografía fonética; morfología; sintaxis; léxico; semántica; pragmática; y comunicación no verbal. Dentro de cada nivel, se han seleccionado los aspectos que, a priori, parecían más relevantes para la diferenciación generolectal.

\section{2 ¿Qué Dice la Sociolingüística de los Generolectos?}

Entendemos el término generolecto como las diferentes formas de hablar y comunicarse en relación con el género que tenga el hablante, es decir, tendremos un feminolecto cuando el hablante sea una mujer, y un masculinolecto cuando el hablante sea un hombre.

Siguiendo a Lozano Domingo (1995: 14), "si admitimos que existen diferencias en la psicología, en la educación y en la socialización de ambos sexos, es fácil colegir que todas ellas se suman y se reflejan en nuestro discurso", esto es, que todas las diferencias internas y externas que se dan entre ambos sexos repercuten directamente en el uso que cada uno hace de las herramientas de comunicación, por lo que el uso del lenguaje constituye uno de los elementos más notables de diferenciación.

Para la sociolingüística en general, y para entender la noción de generolecto en particular, es importante establecer la diferencia que existe entre sexo y género. El sexo es una característica biológica que viene dada desde el momento de la concepción de un nuevo ser, mientras que el género es una dimensión sociocultural que el individuo adquiere al ser socializado (Moreno Fernández 1998: 38).

Una vez establecida esta diferencia, debemos señalar que hay estudios que se centran en la variabilidad basada en el sexo y otros en la variabilidad basada en el género. Siguiendo a Chambers (1994) establecemos la siguiente diferencia:

- Variabilidad basada en el sexo: la variabilidad basada en las capacidades neurofisiológicas verbales de las que disponen ambos sexos. 
- Variabilidad basada en el género: la variabilidad basada en la diferente asignación de funciones socioculturales para hombres y mujeres dentro de una misma comunidad.

En nuestro caso nos centramos en la variabilidad basada en el género, y por ello hablaremos de generolectos, y no de sexolectos, ya que entendemos que las diferentes formas de hablar que presentan hombres y mujeres no están tan condicionadas por el factor biológico como por el sociocultural y que no todos los hombres son masculinos ni todas las mujeres son femeninas.

El hecho de que las mujeres y los hombres se comuniquen de manera diferente es probablemente un universal cultural, pues en todas las culturas los sexos están también socialmente diferenciados, aunque los papeles asignados a cada uno de los géneros varían según la cultura (Silva-Corvalán 2001). Precisamente por este motivo, se crea una expectativa en torno a cómo debe ser el comportamiento de uno y de otro género, lo que lleva a que una misma actitud se valore de forma distinta en un hombre o en una mujer.

"Hombres y mujeres son descritos como grupos sociales opuestos, tanto social como lingüísticamente, pero homogéneos en su interior" (Zernova 2000). En la bibliografía especializada sobre el tema que se ha consultado, los dos géneros aparecen caracterizados en cuanto a sus comportamientos y actitudes, lo que nos permite establecer cuál es el estereotipo de feminidad y cuál es el estereotipo de masculinidad que se acepta actualmente.

\subsection{Estereotipo de Feminidad}

\section{Dulzura, Delicadeza y Expresividad}

Según Lakoff (1995) y Lozano Domingo (1995), a la hora de hablar las mujeres se orientan hacia las personas y los sentimientos, se interesan más por el estado mental que los hombres y también por su propio estatus y por el de los demás. Por estos motivos, las mujeres utilizan un lenguaje que podemos considerar como "emocional". Para entender estas afirmaciones debemos tener en cuenta el tipo de vida que la mujer ha tenido en la sociedad tradicional, que ha creado unos patrones de comportamiento y actuación.

La mujer vivía en comunidad, alrededor de la familia y excluida siempre del espacio público. El silencio de la mujer en todos los ámbitos que no 
fueran reducidos o familiares se justificaba por su inferioridad intelectual y su incapacidad para llevar a cabo las tareas que se destinaban al hombre.

Fuera del espacio privado, las actividades de la mujer eran más sociales que las del hombre. Estaban familiarizadas con las actividades de grupo, limitadas a un mundo femenino. No accedían a ningún tipo de instrucción que les permitiera tener preocupaciones que no se ubicaran en el ámbito familiar.

Entre sus tareas estaba la de cuidar a la familia, a los niños y a los maýores de casa, con quienes se comunicaban, compartían sus razonamientos y expresaban su afecto. La conversación era, para ellas, una forma de organizar la vida a su alrededor.

Pese a que esta forma de vida ha evolucionado mucho acorde con la inserción de la mujer en la vida pública, estos patrones han sido heredados a través de las generaciones y todavía hoy en día se utilizan para describir a la mujer.

\section{Conservadurismo/Innovación}

Se ha dicho que la mujer es más conservadora que el hombre cuando se trata de aceptar cambios en la lengua pero, en los últimos años, numerosos estudios en el campo de la sociolingüística lo han desmentido.

Como apunta Labov, "el ritmo en la progresión y en la orientación del cambio lingüístico debe mucho a la especial sensibilidad de las mujeres respecto al conjunto del proceso" (Labov 1972a: 374).

Cuando se dice que una variedad es mejor o más prestigiosa que otra, se está haciendo mención a las connotaciones de estatus de que goza en una sociedad y que le son atribuidas por los propios hablantes en base a razones sociales y no lingüísticas (Lozano Domingo 1995: 142).

Generalmente, la mujer se muestra proclive a la innovación cuando el cambio se produce desde arriba, es decir, cuando se hace de forma consciente y hacia una variante prestigiosa.

El hecho de que el habla femenina se caracterice por una mayor presencia de variantes lingüísticas prestigiosas se ha interpretado de distintas maneras.

Por un lado, se considera que el uso de la variedad estándar por parte de las mujeres es un modo de intentar elevar su estatus y valor en la sociedad. En palabras de Coates: 
Women are implicated in change particularly when it is in the direction of prestige standard: this leads to a new explanation, replacing conservatism (which is clearly inadequate) with status consciousness on the part of women (Coates 1989: 15).

Por otro lado, se ha incidido en la importancia que la mujer tiene en la socialización de los niños. A la hora de educar a sus hijos, prefiere utilizar la variedad estándar de la lengua.

\section{Corrección y Prestigio Abierto}

Silva-Corvalán considera que:

La mayor sensibilidad de las mujeres hacia normas de conducta "correcta" se demuestra además en el hecho de que se autocorrigen mucho más que los hombres en contextos formales, aun cuando en el habla informal aparezcan como impulsoras de una variante innovadora (Silva-Corvalán 2001: 97).

Al ser las mujeres más conscientes del lenguaje que utilizan, se considera el lenguaje de la mujer como ultracorrecto. Además, ellas también reconocen que existen diferentes formas de hablar según la situación comunicativa en que se encuentran y que hacer un buen uso del lenguaje significa saber adaptarse a cada contexto. Lozano Domingo (1995) observó que al producirse el paso de un estilo menos formal a uno más formal la mujer aumentaba considerablemente el uso de las variables consideradas más prestigiosas.

En este sentido, la mujer se asocia al concepto de prestigio abierto, que está relacionado con el uso de las variedades estándares por considerarse estas las más prestigiosas dentro de la sociedad.

\section{Cortesía}

Siempre se ha dicho que las mujeres son más corteses que los hombres. Según Lakoff (1995), esta actitud está relacionada con el hecho de que la mujer es la depositaria de la moralidad y el civismo, frente a la brusquedad que presentan los hombres. 
No está bien visto que ellas se enfaden, alcen la voz, ni demuestren agresividad verbal. No se admiten insultos, tacos, ni críticas, pero tampoco preguntas indiscretas, ya que rompen el ideal de dulzura que las caracteriza.

Ya desde pequeñas se les inculca que "decir tacos no es propio de señoritas educadas, sino de camioneras o marimachos"(Lozano Domingo 1995: 122).

Siguiendo a García Mouton (2003), podemos señalar los principales comportamientos como característicos de la cortesía femenina:

- sacar temas de conversación agradables;

- evitar los temas conflictivos;

- recurrir a la indirecta;

- evitar las palabras ofensivas;

- suavizar con los gestos;

- emplear cumplidos.

Como bien señala Lozano Domingo (1995) el hecho de que las mujeres adopten formas de cortesía más a menudo que los hombres no significa que tengan menos seguridad en lo que dicen, tal y como algunos autores afirman, sino que no ven necesario poner énfasis en su convencimiento, prefieren hacerlo en lograr un ambiente tranquilo e ideal. Ellas hablan con la atención puesta en el acto comunicativo en sí y también en los participantes que intervienen en este.

\section{Solidaridad}

La solidaridad es una relación simétrica entre dos personas. En la conversación, se considera a las mujeres como solidarias y cooperativas porque las relaciones que establecen con los demás son igualitarias. Ellas se sitúan al mismo nivel que su interlocutor y no tienen el afán de sentirse superiores a este.

\section{Inseguridad}

Lakoff (1995: 113) considera que "las mujeres carecen típicamente de fuerza para imponerse, como mínimo, en más contextos que los hombres".

Se ven obligadas a satisfacer la representación social que se les ha transmitido desde la infancia, comportándose de acuerdo a su género, tal y como la 
sociedad espera que lo hagan. Por este motivo, se argumenta su inseguridad frente al género opuesto y por ello se justifica también el uso de todas las formas de cortesía y su particular manera de entender la conversación.

\subsection{Estereotipo de Masculinidad}

\section{Independencia}

A diferencia de las mujeres, los hombres se orientan hacia los objetos y se interesan por el mundo real y por las situaciones (Lakoff 1995; Lozano Domingo 1995). Por ello se ha considerado que utilizan un lenguaje "lógico".

En la sociedad tradicional, el hombre practicaba labores que se hacían en solitario, como cazar, cuidar el ganado...p por lo que no establecía relaciones con otras personas ni vivía situaciones en las que debiera compartir su pensamiento y, por lo tanto, apenas tenía comunicación con los demás. Por este motivo, su forma de comunicar es diferente, más utilitaria e independiente.

\section{Competitividad}

El lenguaje de los hombres se ha considerado competitivo si se compara con el de las mujeres, ya que la conversación para ellos es una forma de intercambiar información con el locutor más que una manera de estrechar lazos con este. Ellos se centran únicamente en el contenido de la conversación y no en quienes forman parte de ella.

Según Lozano Domingo (1995: 186), "los hombres suelen hablar más de sí mismos, normalmente en confrontación a un oponente, porque ven el mundo como una lucha en la que sus capacidades se juzgan constantemente".

\section{Seguridad}

Para los hombres, compartir sus problemas no solo está mal visto, sino que les sitúa en una posición de debilidad que no les agrada. Las posturas que adoptan muestran seguridad y no suelen pedir ni recibir consejos o ayuda. Estos comportamientos demuestran autoridad y firmeza.

Según Lozano Domingo (1995: 148), "los hombres no tienen la inseguridad de las mujeres porque ellos no tienen que marcar su estatus mediante el lenguaje, ya que lo pueden obtener a través del ejercicio del poder". 


\section{Jerarquía y Poder}

En palabras de Moreno Fernández (1998: 50), "el poder supone una relación no recíproca entre dos personas y la no reciprocidad puede estar basada en diferentes realidades: la riqueza, la edad, la fuerza física, la posición social y, en nuestro caso, también en el género."

Esta relación es asimétrica y se contrapone con las posiciones de solidaridad que se presentan en las mujeres.

En la jerarquía humana, los hombres han sido considerados como más poderosos que las mujeres y es precisamente por este motivo que a ellos se les toleran unos comportamientos que en ellas se ven vetados.

\section{Agresividad y Tosquedad}

Para el varón es más permisible utilizar tacos. El valor de agresividad y rudeza atribuido a las expresiones malsonantes les confiere connotaciones de masculinidad que hacen que los hombres no tengan reparo a la hora de decir un taco en más de una ocasión (Lozano Domingo 1995).

Ellos no necesitan marcar su estatus a través del lenguaje y, normalmente, en la educación de los hijos, suelen tener un segundo papel después de la madre. Por estos motivos, el utilizar una variante u otra no les resulta una cuestión tan importante como a las mujeres.

\section{Prestigio Encubierto}

Los hombres no atienden al mismo valor de prestigio que las mujeres. A diferencia de ellas, suelen responder a un tipo de prestigio encubierto que se aleja de lo normativo y en el que aparecen expresiones relegadas al uso del lenguaje masculino como, por ejemplo, los tacos, blasfemias o palabras malsonantes, que se apartan de lo que en la sociedad se considera como prestigioso.

A pesar de las diferencias que hemos señalado entre el estereotipo femenino y masculino, podemos afirmar que cada vez hay más mujeres que se comportan según lo que se marca en la descripción del estereotipo masculino, aunque los hombres no hacen lo mismo con el femenino.

La conducta sociocultural del grupo privilegiado, el que tiene poder, suele ser adoptada por el otro grupo, pero no viceversa. Esto también justificaría 
que actualmente la mujer trabaje en empleos que antes se consideraban de hombres, aunque en contadas ocasiones veremos a un hombre trabajando en empleos que tradicionalmente se han atribuido a las mujeres.

La investigación lingüística no se ha preocupado por la diversidad verbal y pragmática que se da entre mujeres y varones hasta hace relativamente poco tiempo. Las escasas ocasiones en que tal cosa sucedió, se centraron en lenguas amerindias y africanas, como si las comunidades lingüísticas pertenecientes a la cultura occidental estuviéramos totalmente alejadas de esta cuestión (Calero Fernández 2007).

El interés por el estudio de estas comunidades extranjeras más primitivas surgió por tratarse de poblaciones enteras en las que hombres y mujeres hablaban una lengua diferente, lo que representaba el nivel máximo de oposición entre géneros en todos los sentidos. En la cultura occidental no se da una divergencia tan radical entre hombres y mujeres, pero sí que se pueden señalar ciertas diferencias que ayudan a la caracterización de unos y otros.

En los estudios referidos a las diferencias generolectales, podemos destacar como pionero a William Labov $(1966 ; 1972 \mathrm{a} ; 1972 \mathrm{~b})$ ya que es a partir de sus investigaciones en comunidades anglófonas cuando la variable social del sexo empieza a considerarse imprescindible dentro de los estudios de variación lingüística.

Otra aportación distinguida en los estudios de lenguaje y género es el de la profesora Robin Lakoff (1995), quien con su libro dedicado exclusivamente al habla femenina Language and Woman's Place abrió un camino de investigación para otros lingüistas, lo que ha contribuido a que hoy en día podamos tener una amplia bibliografía especializada sobre el tema.

Además de las investigaciones sociolingüísticas que han examinado la influencia que las diferencias entre los sexos/géneros ejercen sobre la lengua, otras disciplinas como la dialectología, la etnografía de la comunicación, la sociología o la psicología se han ocupado de proporcionar teorías formales y datos científicos sobre la asimetría en el lenguaje de hombres y mujeres.

El estilo comunicativo de la mujer siempre ha sido el más estudiado por el hecho de ser el diferente, el que no se ciñe a los patrones que se presentan desde una óptica androcéntrica que solo considera el lenguaje del hombre como el representativo de la comunidad de habla, por ser este el más correcto y, por lo tanto, superior. Además de ser el más estudiado, también ha sido sobre el 
que más tópicos se han creado y por ello es muy importante tener siempre clara la diferencia entre estereotipo y realidad:

To stereotype someone is to interpret their behaviour, personality and so on in terms of a set of common, sense attributions which are applied to whole groups. One crucial point about this is that the attributions are overgeneralised (Coates 1989: 8).

Solo si somos capaces de establecer esta diferencia podremos contribuir con estudios que sean puramente objetivos en relación al lenguaje y que no tengan marcas subjetivas de ideología sexista que manche el estatus de la mujer y la considere periférica e invisible para los estudios científicos, tal y como ha ocurrido en décadas anteriores por parte de disciplinas como la dialectología.

Aunque en el seno de la sociolingüística se hayan hecho muchas afirmaciones que enfrentan el habla de hombres y de mujeres, afortunadamente las investigaciones han ido marginando poco a poco lo subjetivo, dejando su puesto a los hechos probados y a las demostraciones solventes (Moreno Fernández 1998: 36).

\section{Detección Automática de Género}

La detección automática de género es un área de estudio que se ocupa de la implementación de mecanismos que puedan determinar de manera automática si el autor de un texto concreto es un hombre o una mujer, a partir de la observación y la clasificación lingüística de las características que ese texto presenta, sin tener ningún autor como candidato.

Para hablar de los inicios de este tipo de estudios, debemos dar un salto hacia finales de los años noventa del siglo pasado, cuando surgen los sistemas de comunicación mediada por ordenador, que incluyen todo tipo de comunicación interpersonal llevada a cabo en Internet. A partir de la creación de estos sistemas, aparecen lo que conocemos como redes sociales, plataformas creadas con la intención de facilitar la comunicación entre las personas de forma virtual, a través de un dispositivo tecnológico que tenga conexión a Internet. En estas plataformas, los usuarios se crean un perfil para poder interactuar entre sí, intercambiar y compartir información, crear grupos y comunidades que compartan intereses, etc. 
El problema que plantean este tipo de plataformas virtuales es la creación de perfiles de los que no siempre se comprueba la autenticidad, de modo que surge la duda de si la persona con la que estamos hablando o compartiendo información se corresponde realmente con la del perfil con el que nosotros estamos interactuando. Por consiguiente, si la persona real no se corresponde con la del perfil virtual, podemos determinar que estamos frente a un caso de anonimia, ya que no conocemos la identidad de la persona que está detrás del texto.

Para solucionar los problemas de anonimato en las redes, contamos con los estudios sobre determinación automática de autoría en los que se incluyen los estudios de detección automática de género. En ambas disciplinas, se busca crear un perfil lingüístico que permita desvelar la identidad del autor de un texto y en las dos se utiliza una metodología parecida:

- En la determinación de autoría de un texto se parte de la hipótesis del estilo idiolectal del autor, según la cual "cada individuo tiene un estilo comunicativo propio, único e irrepetible" (Queralt 2014: 40) que lo diferencia de todos los demás.

- En la detección automática de género, se parte del estilo generolectal o la expresión del género y se tiene en cuenta la hipótesis ampliamente extendida y debatida de que hombres y mujeres se expresan y comunican de forma distinta y que estas diferencias se marcan a través de un uso asimétrico del lenguaje.

En el primer caso se estudia la variación que se da en un mismo hablante, mientras que en el segundo, la que se da entre dos grupos de hablantes claramente diferenciados (Company 2003).

Como indican Koppel et al. (2002), a la hora de detectar automáticamente el género de una persona que escribe textos breves en Internet surgen algunos problemas que no se encuentran en la atribución de autoría de un texto:

The problem of automatically determining the gender of a document's author would appear to be a more subtle problem than those of categorization by topic or authorship attribution. Nevertheless, it is shown that automated text categorization techniques can exploit combinations of simple lexical and syntactic features to infer the gender of the author of an unseen formal written document with approximately 80\% accuracy (Koppel et al. 2002: 401). 
Entre estos problemas, podemos destacar los siguientes (Cheng et al. 2011: 79):

1. La identificación de género tiene un alto grado de abstracción. A diferencia de la determinación de autoría, el conjunto de posibles autores no está disponible a priori.

2. Normalmente, la longitud del mensaje de texto en Internet es pequeña, si se compara con los documentos de textos tradicionales como, por ejemplo, los libros, cuya determinación de autoría está más estudiada.

3. El formato o la estructura de los textos de Internet puede variar entre usuarios o situaciones debido a las restricciones de tiempo real, como ocurre en el chat, los mensajes instantáneos, etc.

Siguiendo Cheng et al. (2011), podemos dividir el proceso que se lleva a cabo para la detección automática de género en cuatro pasos:

1. En primer lugar, se debe recoger un corpus de mensajes de texto, que será el que proporcionará los datos que después se analizarán.

2. En segundo lugar, se identificarán aquellos rasgos de cada mensaje que sean indicadores significativos del género de la persona que los ha escrito.

3. Después, se extraerá de forma automática el valor de estos rasgos.

4. Finalmente, se construirá un modelo de clasificación para identificar el género del autor a través del mensaje de texto.

Para llevar a cabo este procedimiento resulta indispensable contar con un equipo multidisciplinar, que esté formado por sociolingüistas, lingüistas matemáticos, lingüistas informáticos e informáticos dedicados a la lingüística. Para los casos en que la determinación de autoría suponga una prueba que ayude a resolver un delito, deberán intervenir, además, lingüistas forenses y equipo del cuerpo policial. Cada uno se encargará de los aspectos que tengan que ver con su especialidad y entre todos se creará un sistema que permita identificar el género de la persona que ha escrito el texto y, si fuera necesario, utilizar este material como pruebas para presentar frente a un juez.

Creemos que las dos primeras fases del procedimiento deberían ser competencia de los sociolingüistas, ya que son estos especialistas los que tienen las herramientas y conocimientos necesarios para determinar las variables lingüísticas, que se pueden correlacionar con el género del hablante. 
El trabajo de los sociolingüistas, permitirá obtener dos perfiles lingüísticos determinados: uno para el género masculino y otro para el género femenino, esto es, la caracterización de los generolectos.

Una vez se han discriminado los rasgos característicos de ambos géneros, se podrá pasar a la parte estadística y computacional, que será competencia de los lingüistas matemáticos, los lingüistas informáticos y los informáticos dedicados a la lingüística.

En el presente estudio, no nos ocupamos de la implementación de sistemas de detección automática del género, por ello no incluimos aquí una explicación de los métodos empleados. Quienes estén interesados en la metodología utilizada en la detección automática de género pueden consultar los trabajos de Koppel et al. (2002), Schler et al. (2005), Cheng et al. (2011), Burger et al. (2011) o Alemán et al. (2014).

\section{Generolectos en la Red}

Nuestro objetivo en esta parte es doble: por un lado, nos proponemos establecer un conjunto de patrones lingüísticos que nos permitan diferenciar a hombres y mujeres según su forma de escribir en la comunicación mediada por ordenador; y por otro, queremos comprobar si la caracterización propuesta en la bibliografía sociolingüística sobre la variación de género sigue estando vigente en la comunicación en las redes sociales.

Antes de presentar el análisis realizado, creemos necesario introducir brevemente lo que algunos autores han denominado ciberhabla.

\subsection{Ciberhabla: La Interfaz entre la Oralidad y la Escritura}

En la comunicación mediada por ordenador, concretamente en las redes sociales, se utiliza un tipo de discurso que no pertenece a ninguna de las dos modalidades de habla establecidas - la oral y la escrita- sino que se sitúa en una posición intermedia. El lenguaje utilizado en este tipo de comunicación es conocido como ciberhabla.

Crystal (2002: 38) presenta algunos rasgos que caracterizan y diferencian la oralidad de la escritura. Según este autor: 
- La oralidad transcurre dentro de unos límites temporales, es espontánea, cara a cara, socialmente interactiva, sin apenas estructura, inmediatamente revisable y rica prosódicamente.

- La escritura, por el contrario, se da dentro de unos límites espaciales, está constreñida, carece de contexto visual, es comunicativamente factual, posee una estructura elaborada y es gráficamente rica.

Aunque la ciberhabla se nutre de características que pertenecen a ambas modalidades, "el rasgo más esencial de la conversación virtual es la cualidad oral de los textos escritos" (Yus 2010: 98). En este sentido, estamos frente a un nuevo lenguaje espontáneo y de carácter informal que se manifiesta por escrito pero que presenta unas características diferentes a las de los textos escritos que aparecen en otros medios. Entendemos que la ciberhabla es una forma de texto oralizado.

Según Yus (2010: 106), "el habla ofrece al emisor más recursos contextuales que la escritura para reforzar su intencionalidad de comunicar una determinada información con un enunciado". En los últimos años, estas opciones de contextualización del enunciado escrito con la capacidad de transmitir información no verbal han aumentado enormemente, puesto que los nuevos usuarios no están dispuestos a renunciar a ningún recurso que apoye lo que están diciendo.

Este nuevo uso de la lengua ha abierto un debate acerca de si esta forma de expresión supone una evolución o, por el contrario, un retroceso, ya que las características de la ciberhabla, a menudo, no se corresponden con la normativa lingüística. A pesar de ello, como bien apuntan Araujo \& Melo (2006):

No estamos en presencia del desconocimiento del uso de la lengua, sino de un uso deliberadamente informal, económico y creativo de la misma, con el objetivo de hacer la comunicación más expresiva, más atractiva, más flexible, más lúdica e incluso más elocuente; un uso deliberadamente coloquial, que captura algunos elementos de la oralidad y que se apropia de ellos en un proceso dinámico, creador y desafiante, revelador de una identidad efusiva que se expande en y por la comunicación (Araujo \& Melo 2006).

\subsection{Ortografía Fonética}

Al tratar con textos escritos, no podemos hacer una clasificación fonética tradicional, puesto que carecemos de los rasgos propios de la modalidad oral. 
Es por ello, que nos situamos en el terreno de la ortografía fonética que, según Yus (2010: 199) "consiste en plasmar textualmente el discurso tal y como sería pronunciado de forma oral".

Como bien apunta Llisterri (2002), a partir de las formas ortográficas que aparecen en la lengua de los chats, se pueden detectar algunas características fonéticas del registro coloquial y obtener información sobre el modo en que los hablantes ponen de manifiesto mediante la escritura las formas en principio restringidas a la oralidad.

La presencia de ortografía fonética en nuestro corpus ha sido analizada teniendo en cuenta la clasificación propuesta por Yus (2010). Algunas de las categorías que podemos utilizar para clasificar las alteraciones gráficas que se producen como estrategias de oralización del texto escrito serían las siguientes:

- (Orto)grafía coloquial: reducción coloquial de las palabras debido a su pronunciación en la cadena hablada.

- (Orto)grafía prosódica: representación de patrones prosódicos de la voz recurriendo a repeticiones de letras, uso de mayúsculas y otros signos de puntuación.

- (Orto)grafía homofónica: comprende dos tipos de alteraciones ortográficas del texto que no se corresponden con alteraciones fonéticas paralelas que pudieran justificarlas:

- Sustituciones léxicas: escribir alguna palabra (o parte de la palabra) cuya pronunciación es igual o similar a la pretendida pero que, debido a su menor longitud, se adecua mejor a la exigencia de rapidez y, en nuestro caso, de espacio.

- Sustituciones grafémicas: sustituir una grafía por otra. El caso más palpable en español es el uso frecuente de la $k$ como sustituto de $q u$.

Los casos en los que se utiliza ortografía coloquial son mayores en las mujeres que en los hombres. Ejemplos de este fenómeno aparecen en 8 mujeres que lo utilizan en un total de 63 ocasiones, frente a 2 hombres que lo hacen en 14 ocasiones (Figura 1).

Estos datos mostrarían que las mujeres son las que más utilizan un recurso ortográfico propio de la escritura de los chats, alejándose así de la normativa lingüística. En este sentido, los hombres serían más correctos que ellas, con lo cual no se cumpliría la característica de la hipercorrección atribuida al género femenino en la bibliografía sociolingüística. 


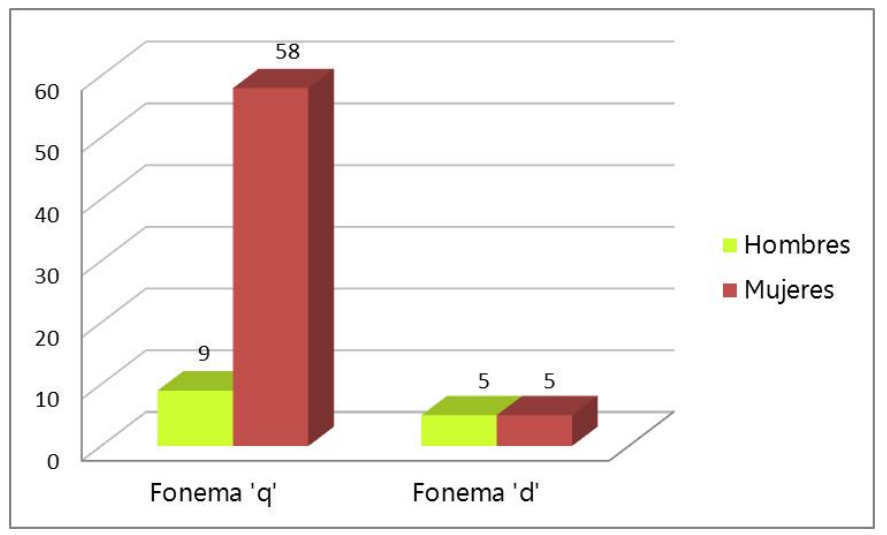

Fig. 1. Ortografía coloquial.

Las partículas que y de son las que sufren la reducción de la grafía vocálica. Cabe destacar que las ocasiones en las que esto ocurre son muy escasas, teniendo en cuenta que la mayoría de estas partículas forman parte de dos de las categorías gramaticales que presenta un mayor número de términos en relación al total. Estas son las conjunciones y las preposiciones.

Los casos de ortografía prosódica son los más abundantes en la comunicación mediada por ordenador. En la comunicación virtual, tenemos la necesidad de recurrir a elementos textuales que nos ayuden a plasmar los factores paralingüísticos, ya que no podemos utilizar la voz para mostrarlos. Las muestras más significativas de ortografía prosódica son:

- el alargamiento de consonantes y vocales;

- el uso de mayúsculas en palabras u oraciones;

- el empleo de los signos de exclamación.

Todas estas características responden a la voluntad de enfatizar el contenido del mensaje. Se busca la forma visual de resaltar aquello que en la comunicación oral se destacaría mediante las características de la voz, como por ejemplo el tono o la intensidad, y mediante la entonación.

Los resultados obtenidos del análisis de nuestro corpus ponen de manifiesto lo siguiente:

- El recurso tipográfico para la compensación vocal del tono más utilizado es la repetición fonemática (cuando se usa para dar énfasis), como en 
los ejemplos (1) y (2). En ocasiones, este recurso también es utilizado para reforzar el contenido semántico, tal y como podemos observar en los ejemplos (3) y (4).

(1) Sujeto 3, hombre, tuit 7: a viviiiiiir

(2) Sujeto 30, mujer, tuit 14: os quierooooooooo

(3) Sujeto 28, hombre, tuit 12: muy muuuy gordo

(4) Sujeto 15, mujer, tuit 3: espera laaaarga

- El uso de mayúsculas puede utilizarse también con el fin de comunicar cualidades vocales como el grito, cuando aparece seguido de signos de exclamación, como en los ejemplos (5) y (6).

(5) Sujeto 1, hombre, tuit 11: NECESITAMOS vuestra AYUDA!!

(6) Sujeto 7, mujer, tuit 12: FELIZ DÍA A TODOS LOS PAPIS DEL MUNDO!!!!

- Los signos de exclamación se utilizarán con el mismo fin enfático, como apreciamos en los ejemplos (7) y (8).

(7) Sujeto 10, hombre, tuit 2: Contigo a muerte!!!!

(8) Sujeto 9, mujer, tuit 5: Viva el carnaval!!!!

- También puede ocurrir que se reproduzcan dos o tres recursos tipográficos en una misma palabra, con el fin de potenciar la intención enfática, como ocurre en los ejemplos (9) y (10).

(9) Sujeto 24, hombre, tuit 3: DIOOSSSSSSS EXISTEEE!!!!

(10) Sujeto 34, mujer, tuit 3: Q nerviooooosssssss q tengoooooo!!!!!

En la bibliografía especializada, se destaca la expresividad como una característica propia de las mujeres frente a los hombres. En los casos de ortografía prosódica, esta generalización no se cumple. Se documentan el mismo número de hombres que mujeres utilizando este recurso (34 informantes de los 40 analizados para cada género). Además, si tenemos en cuenta la frecuencia de uso, los hombres lo utilizan en 330 ocasiones, mientras que ellas en 336, con lo cual la diferencia no es lo suficientemente relevante como para considerar la expresividad, en este caso a través de la ortografía prosódica, un recurso propiamente femenino.

A pesar de la no diferencia apreciable en términos cuantitativos, podemos señalar cierta divergencia a la hora de utilizar uno u otro recurso. Así, como 
muestra la Figura 2, las mujeres utilizan los recursos de alargamiento de vocales y consonantes y las frases exclamativas más a menudo que los hombres; mientras que el uso de mayúsculas se da más entre el público masculino.

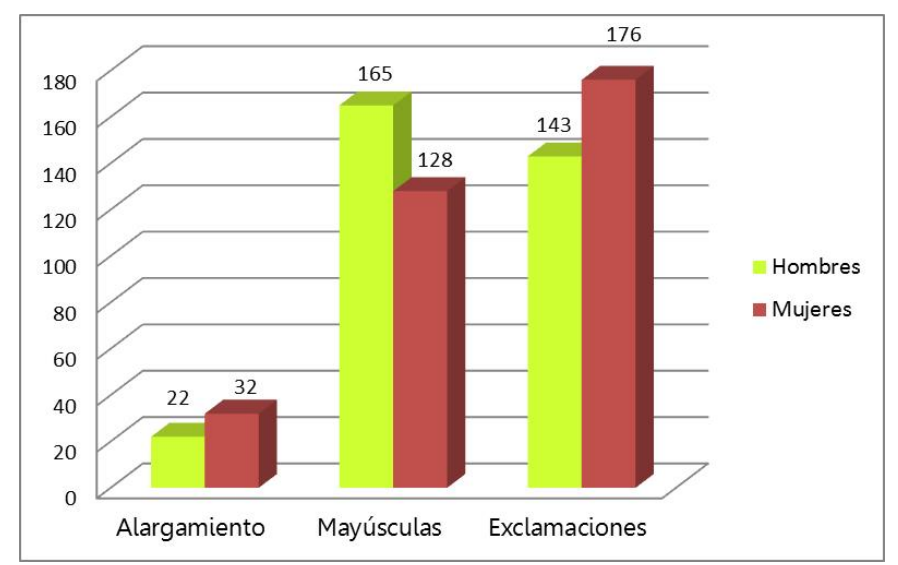

Fig. 2. Ortografía prosódica.

Estos datos no nos sorprenden si tenemos en cuenta la bibliografía, puesto que en ellos se destaca la agresividad y tosquedad verbal de los hombres. Un volumen alto transmite autoridad, seguridad en uno mismo o dominio de la situación, rasgos culturalmente masculinos que se relacionan con actitudes de poder.

Por último, debemos señalar los casos de ortografía homofónica. Concretamente, nos basaremos en las sustituciones léxicas. Las más comunes son las que emplean símbolos matemáticos, ya que la forma de nombrarlos se corresponde con la misma que se emplea para los adverbios más e igual y con la preposición por. Estos rasgos no son muy significativos, puesto que el porcentaje sobre el total es ínfimo. En el caso de los hombres, se han utilizado solo en 5 ocasiones. Dos ejemplos serían (11) y (12). Las mujeres, en cambio, hacen uso de las sustituciones léxicas en 10 ocasiones, como muestran los ejemplos (13) y (14).

(11) Sujeto 7, hombre, tuit 12: cada día os superáis +

(12) Sujeto 15, hombre, tuit 7: y xstarsiempr cerca 
(13) Sujeto 15, mujer, tuit 4: Naturaleza + ejercicio $=$ energía, felicidad $y$ buen vicio

(14) Sujeto 34, mujer, tuit 14: gracias $x$ esos frutos rojos

\subsection{Morfología}

En este apartado, nos centraremos en aspectos que afectan a la morfología. En este caso, será relevante el uso de prefijos, sufijos apreciativos y los acortamientos.

\section{Prefijos}

Nos interesa analizar el tipo de prefijos que han sido utilizados por hombres y mujeres para, de ese modo, dar cuenta de si este rasgo lingüístico es lo suficientemente importante como para ser considerado en la detección automática del género de un hablante.

Lang (1992) clasifica los prefijos en cinco clases diferentes:

1. Prefijos de negación;

2. Prefijos locativos;

3. Prefijos temporales;

4. Prefijos de cantidad y tamaño;

5. Prefijos de intensificación.

En nuestro caso, clasificaremos los prefijos que han aparecido en el corpus, basándonos en la clasificación anterior, en dos grupos:

1. Grupo 1: formado por los prefijos de negación, locativos, temporales y de cantidad y tamaño.

2. Grupo 2: incluye los prefijos de intensificación, ya que parece que son estos en los que se produce una asimetría importante.

Según Lang (1992: 234), "los prefijos de intensificación se utilizan para ampliar morfológicamente el lexema base con el fin de producir un efecto hiperbólico". López García y Morant (1995), Zernova (2000), García Mouton (2003) o Penas (2009), entre otros autores, afirman que la frecuencia en que las mujeres utilizan estos prefijos, sobre todo delante de adjetivos calificativos, 
es mayor que en los hombres, pero, ¿sigue siendo válida esta afirmación en la comunicación mediada por ordenador?

En nuestro corpus se ha analizado un total de 134 prefijos, de los cuales 67 han sido utilizados por hombres y los 67 restantes por mujeres. Si tenemos en cuenta la tipología presentada:

1. El grupo 1 cuenta con un total de 124 prefijos, de los cuales 57 han sido utilizados por 27 mujeres (46\%) y 67 por 30 hombres (54\%). Como podemos ver, en este grupo son los hombres quienes utilizan más la prefijación.

2. En el grupo 2, observamos que 10 prefijos intensificativos han sido utilizados por 8 mujeres, mientras que los hombres no han utilizado ninguno. Se han creado dos palabras utilizando el prefijo re-y ocho utilizando super-. En este caso, sigue siendo válida la afirmación de que las mujeres utilizan más la intensificación que los hombres. A pesar de ello, es sorprendente que se haya documentado un número tan bajo de prefijos de este tipo y que en los 600 tuits de los hombres no aparezca ni tan siquiera un prefijo intensificativo.

\section{Sufijos Apreciativos}

Los sufijos apreciativos se diferencian del resto de sufijos del corpus general en que alteran semánticamente la base, de un modo subjetivo o emocional, sin cambiar su categoría gramatical.

Dentro de este grupo, establecemos la división entre (Lang 1992):

1. Diminutivos, que transmiten una idea de pequeñez o afectividad;

2. Aumentativos, que implican amplia dimensión, fealdad o grandiosidad;

3. Despectivos o peyorativos, que implican desagrado o ridiculez.

En la bibliografía especializada se destaca que, en el ámbito de la sufijación, las mujeres se distinguen de los hombres por la frecuencia de diminutivos.

Los diminutivos también "se utilizan por razones pragmáticas de tipo afectivo, puesto que el uso del diminutivo indica afecto, independientemente del tamaño" (Aguirre 2013: 283). Debido a esta connotación, se suele relacionar el empleo de diminutivos con el habla femenina, ya que, como hemos visto anteriormente, se considera que ellas son más afectivas y emocionales en su conducta lingüística. 
En el análisis de nuestro corpus hemos identificado un total de 27 hombres y 26 mujeres que utilizan esta categoría sufijal. Ellos utilizan los apreciativos en 49 ocasiones, mientras que ellas lo hacen en 46. Si tenemos en cuenta las tres clases de apreciativos que hemos establecido, se producen diferencias en la frecuencia de uso (Figura 3):

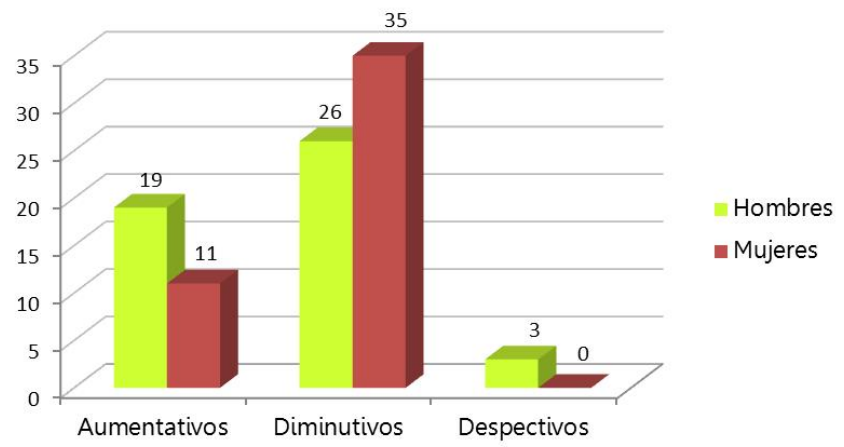

Fig. 3. Sufijos apreciativos.

- Del total de 30 aumentativos aparecen 19 (63\%) utilizados por 14 hombres, cuando en ellas aparecen 11 (37\%), usados por 10 mujeres.

- De los 61 diminutivos utilizados, contamos con un total de 26 (43\%) que son utilizados por 19 hombres y un total de 35 (57\%) usados por 20 mujeres. Los resultados coinciden con las hipótesis que aparecen en la bibliografía. Parece que, debido al carácter afectivo de este tipo de sufijos, son las mujeres quienes hacen un mayor uso de estos.

- En el caso de los despectivos, solo han aparecido 4 hombres que han utilizado 3 de ellos: -uza (gentuza en dos ocasiones), -aco (cabronaco), -aca (perraca). Los despectivos están relacionados con la rudeza, puesto que aportan connotaciones peyorativas al objeto que modifican. En este sentido, no es de extrañar que sean los hombres quienes los empleen, puesto que en la bibliografía especializada se considera que ellos son más groseros que ellas, pero sí que es destacable que del total de 40 hombres analizados solo cuatro los usen. 


\section{Acortamientos}

Llamamos acortamientos o truncamientos a la utilización de una parte de una palabra como variante de la palabra completa. La palabra base no genera un derivado semánticamente diferente de ella misma, pero sí una forma apocopada que con el tiempo puede llegar a ser tan habitual que acabe lexicalizándose y suplantando al término inicial.

Lang (1992) vincula la utilización de acortamientos a determinados contextos sociolingüísticos. La variable sexo podría ser una de las implicadas en estos contextos, puesto que, según López García y Morant (1995: 103), "un rasgo observado en la modalidad lingüística femenina es la existencia de determinados acortamientos léxicos, poco usuales en la gramática varonil". Otras autoras como Aguirre (2013), vinculan este proceso a la informalidad y al uso del registro coloquial, dos características que son propias del contexto en el que se enmarca nuestro corpus.

Los acortamientos que hemos encontrado han sido creados por apócope, es decir, por la pérdida de sílabas finales. Son 19 los hombres que han utilizado alguna palabra en su forma apocopada, mientras que, en el caso de las mujeres, hemos constatado 20 sujetos. En este sentido, si tenemos en cuenta el total de 40 personas analizadas, no se produce diferencia, pero si pasamos a analizar la frecuencia de uso, encontramos disimilitudes.

De un total de 68 acortamientos, los hombres los utilizan en 27 ocasiones (40\%), mientras que las mujeres lo hacen en 41 (60\%).

Cuando los acortamientos afectan a nombres propios reciben el nombre de hipocorísticos. Estos han sido contabilizados junto a los demás casos de acortamiento. En el caso de las mujeres, se han utilizado en 11 ocasiones, mientras que en los hombres, en 8. Si, como señala Almela (1999: 203), "la causa de la aparición de estos vocablos acortados suele ser la necesidad de manifestar un valor apreciativo", no es de extrañar, una vez más, que predominen en el grupo femenino.

Los datos bibliográficos se corroboran si tenemos en cuenta la aportación de Aguirre (2013), puesto que al situarnos en un contexto informal, la mitad de cada grupo utiliza estas formas. En cambio, si contrastamos los datos con la teoría de López García y Morant (1995), no podemos afirmar que se cumplan por completo sus declaraciones, ya que aunque sí que son las mujeres quienes más utilizan acortamientos, estos están también presentes en el lenguaje de los hombres. 


\subsection{Sintaxis}

En esta parte analítica vamos a tratar las estructuras incompletas, puesto que es uno de los elementos sintácticos en los que se dice que se produce una mayor diferenciación entre ambos géneros. Se trata de un aspecto lingüístico que lleva implícito el uso de oraciones más o menos complejas y de elipsis de elementos integrados en la oración.

\section{Estructuras Incompletas}

La definición de la oración a partir de su estructura interna impone el requisito de que estén presentes los constituyentes que la componen: el sujeto y el predicado. A pesar de ello, existen oraciones en las que dicha estructura no aparece. Estas se conocen como estructuras incompletas o fragmentos. Di Tullio (2010) considera que gramaticalmente estas secuencias no dejan de ser sintagmas nominales, ya que no solo carecen de todas las propiedades flexionales que caracterizan a la oración, sino que tampoco resulta viable el análisis en términos de sujeto y predicado. En este sentido, se entienden como enunciados no oracionales en los que se producen elipsis contextuales: se suprimen elementos que se pueden sobreentender atendiendo al sentido oracional.

Zernova (2000) y otros autores insisten en remarcar la tendencia de las mujeres a emitir juicios sueltos creados por estructuras sintácticas más cortas y simples que las de los hombres. Estos utilizan oraciones más largas y complejas, donde estos juicios se incluyen en ellas.

Al analizar nuestro corpus, hemos localizado 33 mujeres y 30 hombres que escriben alguno de sus tuits en forma de estructuras incompletas, un número bastante alto teniendo en cuenta que son 40 los sujetos analizados en cada grupo. En el caso de ellas, han sido 99 los tuits en los que se ha reproducido esta estructura oracional, mientras que en ellos, ha ocurrido en 67 ocasiones.

Teniendo en cuenta estos números, la relación entre el total de mujeres y hombres y la frecuencia de uso demuestra que las mujeres son las que más se han servido de este recurso, tal y como indicaba la bibliografía especializada.

Algunos ejemplos del tipo de estructuras incompletas que se han analizado y que ocupan un único tuit son los siguientes:

(15) Sujeto 1, hombre, tuit 3: Team!

(16) Sujeto 18, hombre, tuit 7: Toma luna!! 
(17) Sujeto 1, mujer, tuit 3: A por la semana!!

(18) Sujeto 9, mujer, tuit 9: Nuevo post en el blog y fotitos nuevas.

En algunas ocasiones, se introducen estructuras incompletas mezcladas con estructuras oracionales completas dentro de un mismo tuit. Estas no se han contabilizado a la hora de abordar nuestro análisis.

Desde nuestro punto de vista, este tipo de fusiones oracionales no responden tanto a la diferenciación del tipo de estructuras utilizadas entre hombres y mujeres, como a la forma de expresarse de unos y otros (recordemos que se encuentra limitada por la restricción de extensión de 140 caracteres). Las mujeres prefieren utilizar un mismo tuit para introducir ideas diferentes referidas a un mismo tema, de modo que utilizan oraciones fragmentadas, con elisiones de algunos de sus constituyentes y separadas por algún signo de puntuación. Los hombres, en cambio, prefieren generar más tuits y que cada uno trate una idea concreta, con lo cual se pueden permitir utilizar unas estructuras más complejas y complicadas en las que unas oraciones se coordinen o subordinen a otras.

A pesar de estas consideraciones, estamos hablando de una tendencia general, ya que encontramos casos de hombres que también crean estructuras de este tipo. Algunos ejemplos serían los siguientes:

(19) Sujeto 23, hombre, tuit 1: Domingo bien acompañado. ¿Los perros se parecen a sus amos?

(20) Sujeto 27, hombre, tuit 10: La otra cara del ballet profesional. Poco reconocimiento tienen.

(21) Sujeto 20, mujer, tuit 3: Pffff. Otro año igual. Se nota un montón que copian a los Goya.

(22) Sujeto 30, mujer, tuit 14: Con mis amigas!!!! Os quierooooooooo.

\subsection{Léxico}

Los aspectos léxicos que consideramos que presentan datos relevantes en cuanto a la diferenciación entre ambos sexos son el uso de palabras malsonantes, los extranjerismos y las interjecciones y onomatopeyas. 


\section{Palabras Malsonantes}

Según el ideal de feminidad estipulado, la mujer debe evitar las expresiones hirientes, agresivas o soeces e inclinarse por los insultos menos bruscos (Lozano Domingo 1995; García Mouton 2003; Jespersen 2007). A los hombres, por el contrario, estas expresiones les son permitidas.

En el empleo de palabras malsonantes, se han relacionado las variables de sexo y de clase social. Así, el mayor empleo de tacos se considera que se da por parte de varones e individuos con menor nivel cultural, mientras que su menor frecuencia se da entre las mujeres y las personas con un mayor nivel de instrucción (Lozano Domingo 1995).

En nuestro corpus se cumplen las características señaladas en los estudios sobre el tema. Los casos en los que se produce un mayor empleo de palabras malsonantes e insultos se da en 9 hombres, en 30 ocasiones. Por el contrario, es destacable que solamente 3 mujeres emplean cuatro expresiones malsonantes (puta, reeeeostia y mierda, en dos ocasiones). A pesar de la gran diferencia entre hombres y mujeres, cabe destacar que el empleo de estas expresiones es mínimo teniendo en cuenta que partimos de un corpus de 80 individuos.

Estos datos se pueden analizar desde dos perspectivas diferentes:

1. La primera de ellas es por la continencia verbal que se da en esta red social por parte de los personajes famosos. Al tratarse de una red pública en la que todo el mundo puede leer los mensajes que quedan plasmados de forma escrita, existe una mayor preocupación por aquello que se escribe. Esto no ocurre de la misma forma en los medios de comunicación, donde algunos de estos personajes, al tratarse de un medio oral y espontáneo, resultan más vulgares.

2. La segunda, porque, en el caso de las mujeres, debido a que, como veremos más adelante, son más corteses que ellos y responden a un prestigio abierto, dan réplica a insultos y acusaciones utilizando otras expresiones en lugar de palabras malsonantes. De ese modo, demuestran su capacidad de adaptación a las diferentes situaciones comunicativas.

\section{Extranjerismos}

La red contribuye en gran medida a la propagación e incorporación de extranjerismos. Actualmente, el uso de extranjerismos en las redes sociales es 
un signo que representa distinción y modernidad: eres más cool al decir weekend en lugar de fin de semana, shooting en lugar de sesión de fotos o que estás in love en lugar de que estás enamorado. La lista de ejemplos sigue y se alarga mucho más y, al parecer, cada vez lo hará en mayor medida.

Existen instituciones y organismos lingüísticos como la Real Academia Española o la Fundéu que recomiendan evitar el abuso de extranjerismos cuando son innecesarios, es decir, cuando existe la palabra equivalente en español, pero a pesar de ello, consideran que "la incorporación del extranjerismo es, en cualquier caso, un fenómeno natural en las lenguas que no debe censurarse" (Tascón 2012: 97).

Se considera que las mujeres son una vía a la introducción constante de extranjerismos (García Mouton 2003). En los contextos formales, son las impulsoras de las variantes prestigiosas, relacionadas con el uso de la lengua estándar. En cambio, en los contextos informales, como es el caso de Twitter, lo son de variantes innovadoras. Un ejemplo es el uso de términos que provienen de otras lenguas que presentan un estatus social más elevado, como ocurre con el inglés.

En nuestro corpus, se dan cuatro fenómenos diferentes relacionados con el uso de lenguas extranjeras en hombres y mujeres:

1. Se introducen palabras o expresiones extranjeras (los propiamente dichos extranjerismos) en el discurso escrito en español.

2. Se escriben tuits completos en lenguas extranjeras.

3. Aparece la mezcla de oraciones, o partes de esta, en español y en otra lengua extranjera en un mismo tuit (code-switching).

4. Se introduce la traducción del contenido del tuit al lado de este en alguna lengua extranjera.

Consideraremos extranjerismos todas las palabras, expresiones y oraciones que estén en una lengua que no sea el español. De ese modo, establecemos dos grupos:

- por un lado, las palabras o expresiones simples (Fenómeno 1)

- y, por el otro, las oraciones o fragmentos de estas (Fenómenos 2, 3, 4)

Tanto el término o expresión como la oración, contarán como una sola unidad de análisis. Los resultados obtenidos pueden resumirse de la siguiente manera: 
1. Fenómeno 1: Si solo tenemos en cuenta este aspecto, son 22 los hombres que utilizan extranjerismos, frente a las 17 mujeres que lo hacen, del total de 40 en ambos casos. En esta ocasión, son los hombres los que introducen más voces extranjeras en sus discursos, aceptadas en español o no.

2. Fenómeno 2: El segundo fenómeno se da casi siempre en inglés y responde a la voluntad de modernidad, relacionada con el estatus de la lengua extranjera, puesto que actualmente es una de las lenguas con más potencial en las redes sociales y en el mundo entero. Este fenómeno se da en 10 mujeres y solo en 2 hombres.

3. Fenómeno 3: En el tercer fenómeno, se produce la yuxtaposición de oraciones enteras o fragmentos de oraciones de lenguas diferentes en una misma intervención, esto es, en un mismo tuit. Este fenómeno es conocido como cambio de código o code-switching y se da en hablantes o grupos sociales bilingües que conocen los dos códigos, en nuestro caso, el español y el inglés en la mayoría de ocasiones. Se trata de una situación que, otra vez, se da de forma más frecuente en ellas que en ellos, ya que son 4 las mujeres que lo utilizan frente a 2 hombres.

4. Fenómeno 4: El último proceso se utiliza con la intención de llegar a un público más amplio, para que los usuarios que desconozcan el español puedan entender el mensaje. Este fenómeno se da casi por igual en hombres y en mujeres, 4 frente a 3 respectivamente.

Los resultados obtenidos en el estudio confirman los hechos que aparecen en la bibliografía especializada sobre el tema en el sentido de que hay 25 mujeres que utilizan extranjerismos, correspondientes a los cuatro fenómenos, frente a 23 hombres que lo hacen, de un total de 40 mujeres y 40 hombres.

La diferencia a nivel de usuarios es mínima, por lo que nos hemos basado en la frecuencia de uso de extranjerismos en unos y en otros para mostrar que dependiendo de cuál sea el fenómeno de los cuatro que hemos marcado, serán los hombres o las mujeres quienes más los utilicen en su discurso. A pesar de las diferencias existentes, el número total de extranjerismos utilizados ha sido de 64, tanto en hombres como en mujeres (Figura 4).

En los casos correspondientes a los fenómenos 1 y 4, son los hombres los innovadores, mientras que en los correspondientes a los fenómenos 2 y 3 , son las mujeres las que se inclinan hacia unas variantes en otro idioma que gozan de más prestigio en la sociedad. 


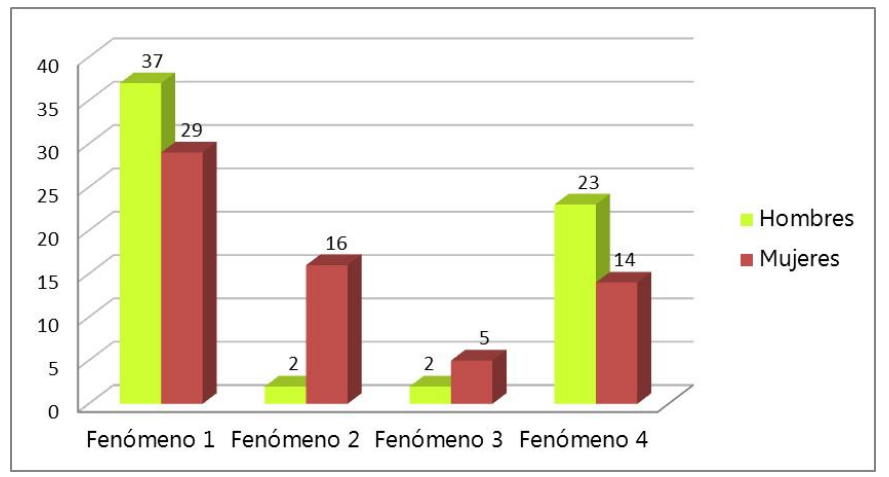

Fig. 4. Extranjerismos.

\section{Interjecciones y Onomatopeyas}

Las interjecciones son palabras invariables que destacan por su relevancia expresiva. Como bien señala Vigara (1992: 105) son "producto de una cierta tendencia espontánea a reducir la expresión a lo "afectivamente imprescindible". Estas se encuentran sintácticamente aisladas y presentan una entonación exclamativa. Al igual que las onomatopeyas, destacan en el plano de la interacción, por lo que es frecuente su aparición en el discurso oral, y en nuestro caso, también en la escritura oralizada que caracteriza el lenguaje de las redes sociales.

Según su significado, podemos establecer dos grupos (Vigara 1992):

- Interjecciones propias: son términos carentes de significado y estereotipados que se fijan en una lengua. Se ha considerado que equivalen a oraciones, puesto que presentan un sentido completo y una entonación independiente, y no a partes de la oración, ya que no cumplen en ella ninguna de las funciones descritas en las gramáticas. Al carecer de significado, especifican circunstancialmente su sentido por medio de la entonación y el contexto en el momento del acto comunicativo.

- Interjecciones impropias: son términos desemantizados que pueden proceder de cualquier esfera vital. Aisladas también entonacionalmente, sirven como las anteriores para el momentáneo desahogo emocional del hablante y especifican también circunstancialmente su sentido. 
López García y Morant (1995) especifican una clasificación más detallada dentro de cada uno de los grupos. Dependiendo de la función que desempeñen, las interjecciones propias se dividen en:

- Expresivas: cuando manifiestan sensaciones y emociones del hablante;

- Apelativas: cuando sirven para establecer el contacto con el oyente antes de emitir el mensaje;

- Representativas: cuando son la imagen viva de una acción.

Por su parte, dentro de las interjecciones impropias, existen algunas que se consideran expresivas, en el sentido de que manifiestan sensaciones y emociones del hablante. En ese caso, se establece una subdivisión entre:

- Obscenas: palabras cuyo significado atenta contra el sentido del "pudor";

- Blasfemas: alusiones injuriosas contra la divinidad, cuyo uso ha sido siempre relegado a los hombres.

En nuestro corpus, el uso total de interjecciones se ha dado en 159 ocasiones, de las cuales 20 corresponden a interjecciones propias (13\%) y 139 a impropias (87\%).

6 hombres utilizan las propias en 7 ocasiones (35\%), mientras que $11 \mathrm{mu}-$ jeres, en 13 (65\%). Podemos considerar este tipo de interjecciones más subjetivas, puesto que al no estar lexicalizadas como las impropias, surgen según la personalidad de cada individuo (Tabla 1 ).

Respecto a las impropias, 33 hombres las utilizan en 77 ocasiones (55\%), mientras que 31 mujeres, en 62 (45\%). Este dato resulta relevante porque muestra que los hombres de nuestro corpus, en este sentido, son más expresivos que las mujeres, algo que en la bibliografía nunca se contempla.

Otro dato importante de este grupo lo encontramos si tenemos en cuenta la subdivisión entre interjecciones obscenas y blasfemas. En este caso, se confirma la teoría de López García y Morant (1995), ya que en nuestro corpus son los hombres quienes las utilizan, concretamente 1 hombre utiliza 2 blasfemas y 6 hombres utilizan 8 obscenas, en contraposición al grupo de mujeres, en el que no hay ninguna que las utilice.

Lo que podemos destacar de este resultado es que a pesar de la clara diferencia entre ambos géneros, el número de hombres que utilizan este tipo de palabras es mínimo si tenemos en cuenta el total de 40 con el que contamos. 


\begin{tabular}{|l|l|l|}
\hline \multicolumn{2}{|c|}{ INTERJECCIONES PROPIAS } \\
\hline \multicolumn{1}{|c|}{ Mujeres } & \multicolumn{1}{c|}{ Hombres } \\
\hline Suj. 3, tuit 7: ohhhh & Suj. 40, tuit 14: oye & \multicolumn{1}{c|}{ Expresivas } \\
Suj. 6, tuit 10: eh & & Suj. 2, tuit 13: oh \\
Suj. 12, tuit 3: ooohhhh & & Suj. 12, tuit 15: buah \\
Suj. 13, tuit 7: jo & Suj. 19, tuit 14: eh \\
Suj. 15, tuit 3: ui & & Suj. 24, tuit 3: buaaaaahhhhh \\
Suj. 21, tuit 4: ooohhh & & Suj. 37, tuit 14: yeah \\
Suj. 22, tuit 13: ah & & \\
Suj. 29, tuit 5, 11: ah & & \\
Suj. 31, tuit 4: yujuuuuuuu & & \\
Suj. 38, tuit 12: bah & & \\
\hline
\end{tabular}

Tabla 1. Interjecciones propias.

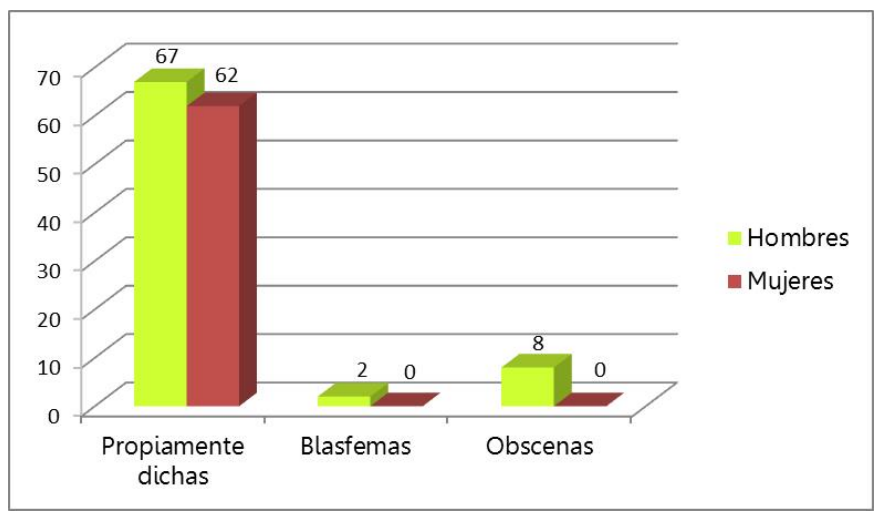

Fig. 5. Interjecciones impropias.

Parece ser que, en nuestro corpus, la tosquedad atribuida al género masculino tiene poca representación.

Las onomatopeyas, al igual que las interjecciones, son palabras invariables que destacan por su papel notablemente enfático, pero no constituyen clases gramaticales de palabras, sino que son más bien signos lingüísticos que se forman por imitación de un sonido, ruido o incluso un fenómeno visual, con el que también están vinculadas semánticamente. No son frecuentes en el lenguaje escrito formal, pero en el contexto en que nos situamos, son un 
recurso del código oral que recuerda, de nuevo, la coloquialidad de la comunicación.

En el caso de las onomatopeyas, hemos encontrado un número muy reducido: en ellas, solo aparecen en 8 ocasiones, mientras que en ellos, en 16 .

Al tratarse de un recurso expresivo enfático, la bibliografía lo relaciona con el habla femenina, pero como vemos en nuestro corpus, son ellos los que más las utilizan, con lo cual los datos habituales en la bibliografía sociolingüística no se ajustan a lo que parece ocurrir en la comunicación mediada por ordenador.

Las onomatopeyas que se utilizan para ejemplificar el sonido de la risa son las más numerosas, puesto que representan el $62 \%$ de las onomatopeyas totales. Resulta habitual verlas repetidas, tanto en hombres como en mujeres, para remarcar o regular la intensidad de su significado. "Un simple $j a$ equivaldría a una risa irónica, que no denota alegría; un jaja, a una risa sincera; y un jajaja, a una carcajada" (Tascón 2012: 144).

\subsection{Semántica}

En este apartado, vamos a centrarnos en los tipos de adjetivos que se utilizan según la variación generolectal y en los campos semánticos más frecuentes en la comunicación de hombres y mujeres.

\section{Adjetivos}

Para clasificar los adjetivos, nos basaremos en la clasificación sintáctica que propone Di Tullio (2010) que está condicionada por distinciones semánticas, que son las que nos interesan en este apartado. Podemos establecer tres clases de adjetivos:

1. Adjetivos calificativos: predican cualidades o propiedades de los sustantivos a los que modifican. Se pueden establecer dos subclases:

a) Descriptivos: designan una propiedad objetiva no inherente en el significado del sustantivo;

b) Evaluativos: proporcionan una propiedad que el hablante juzga como caracterizadora del objeto. Indica una valoración o una propiedad.

2. Adjetivos relacionales: vinculan al sustantivo con un determinado ámbito. Son derivados de sustantivos, por lo que resultan equivalentes a un SP encabezado por de. 
3. Adjetivos adverbiales: no denotan propiedades, cuantifican o localizan.

Dentro de los adjetivos calificativos evaluativos es importante destacar los adjetivos con valor elativo. Se trata de adjetivos que indican el grado extremo de una propiedad graduable y ponderan enfáticamente la evaluación del hablante sobre una determinada propiedad. Precisamente por tener este valor subjetivo y expresivo han sido relacionados con el generolecto femenino.

Como ya hemos visto, algunos autores insisten en la expresividad como una característica inherente en el comportamiento de las mujeres. Esta expresividad se refleja en el lenguaje a través de formas diferentes y una de estas formas es el uso de los adjetivos.

García Mouton (2003: 80) considera que las mujeres "recurren más que el hombre a palabras con carga emocional clara". Penas (2009) destaca que la mujer "emplea adjetivos apreciativos como divino, encantador, lindo o mono", y Zernova (2009) se centra en que las mujeres tienden a utilizar adjetivos cuya semántica representa de modo notable el aspecto apreciativo o expresivo del objeto, mientras que en los hombres predominan unidades adjetivales de carácter descriptivo.

Si tenemos en cuenta aportaciones como las anteriores, las mujeres deberían ser las que utilizaran más los adjetivos calificativos evaluativos y los elativos pero, ¿se cumple esta afirmación en la comunicación a través de Twitter?

En nuestro análisis nos centraremos solo en los adjetivos calificativos, puesto que, según la bibliografía consultada, son los que interesan para establecer las diferencias entre hombres y mujeres. A pesar de ello, los relacionales y adverbiales se pueden encontrar contabilizados en la Figura 6.

El uso total de adjetivos calificativos del tipo evaluativo ha sido de 410. De estos, las 40 mujeres han utilizado un total de 223 (54\%), mientras que 39 hombres, un total de 187 (46\%). Si tenemos en cuenta los descriptivos, se han utilizado en 483 ocasiones, 216 veces por las 40 mujeres (45\%) y 267 en 40 hombres (55\%). Respecto a los elativos, se han utilizado un total de 22 veces: 11 mujeres los han utilizado en 12 ocasiones, mientras que 7 hombres los han usado en 10.

Una vez más, se confirman los datos bibliográficos. Son las mujeres las que más utilizan los adjetivos calificativos, aunque la diferencia con el género 


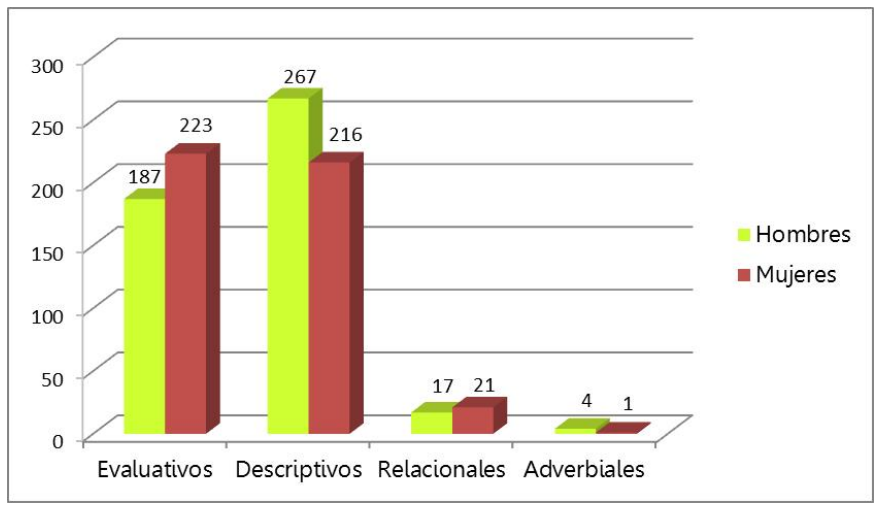

Fig. 6. Adjetivos.

masculino no es tan amplia como cabría esperar. Es destacable el caso de los elativos, ya que se consideran relegados al lenguaje femenino y como vemos, los hombres también los utilizan.

\section{Los Campos Semánticos: La Temática de la Comunicación}

En general, se afirma que las mujeres centran su atención en las personas y en sus emociones y las de los que las rodean, a diferencia de los hombres, que se interesan por temas profesionales y por las situaciones del mundo real (Lakoff 1995; Zernova 2000; García Mouton 2003). Algunos autores señalan que en ellas destacan las narraciones de un pasado reciente, centradas en pequeños detalles de la vida cotidiana; mientras que en ellos, las narraciones se ubican en un pasado distante y están relacionadas con temas típicamente masculinos como coches, deportes y últimas tecnologías (Coates 2003).

En nuestro corpus, hemos podido observar que solo parte de estas afirmaciones se cumplen. Es cierto que las mujeres se muestran más atentas a sus sentimientos y a las relaciones interpersonales y que ellos no lo hacen con tanta frecuencia, lo que se demuestra en el uso de los emojis relacionados con las muestras de afecto y cariño, que aparecen en 190 ocasiones más que en ellos, pero a pesar de esta diferencia, los dos grupos se centran en sí mismos, en su día a día, su rutina profesional y sus aficiones.

En ellas destacan las actividades relacionadas con el culto al cuerpo y por ello utilizan más palabras y emojis relacionados con el campo semántico de la moda y la belleza. 
A diferencia de lo que se indica en la bibliografía, los hombres de nuestro corpus son más propensos a comentar datos relativos a la actualidad, mientras que en ellas esta información es más frecuente en las mujeres que ejercen profesiones donde les es requerido, como las periodistas o la vicepresidenta del gobierno.

\subsection{Pragmática}

Spencer-Oatey (2008) considera que la variación pragmática se puede analizar desde diferentes ámbitos: el ilocutivo, el del discurso, el no verbal, el participativo y el estilístico. Para ver si existen diferencias entre hombres y mujeres, en este noveno apartado nos centraremos en el ilocutivo, que se corresponde con el estudio de la realización lingüística de los actos de habla, y el estilistico, que hace referencia al uso de las formas de tratamiento y al registro.

\section{Actos de Habla}

La Real Academia define los actos verbales o actos de habla como las "acciones que se llevan a cabo empleando palabras" (2009: 3118). Se dice que los actos de habla constituyen acciones en el sentido de que no se limitan a expresar o a describir información.

Los actos de habla se definen como enunciados que no pueden ser verificados en términos de verdad. Preguntas, exclamaciones u órdenes, son ejemplos de este tipo de enunciados.

Austin (1962) introduce la teoría y Searle (1969) la sistematiza agrupando los actos de habla en cinco categorías:

1. Asertivos, que dicen algo acerca de la realidad;

2. Directivos, que pretenden influir en la conducta del interlocutor;

3. Compromisivos, que condicionan la ulterior conducta del hablante;

4. Expresivos, con los que el hablante manifiesta sus sentimientos o sus actitudes;

5. Declarativos, que modifican la realidad.

Para el análisis de los actos verbales de nuestro corpus, tendremos en cuenta la clasificación aportada por Searle. Debido al gran volumen de enunciados en cada tuit, nos hemos limitado a recoger un total de 1.000 actos de habla de forma aleatoria, 500 en hombres y 500 en mujeres. 
Tras haber analizado estos actos de habla, llegamos a la conclusión de que no existen diferencias significativas entre hombres y mujeres en la comunicación a través de Twitter.

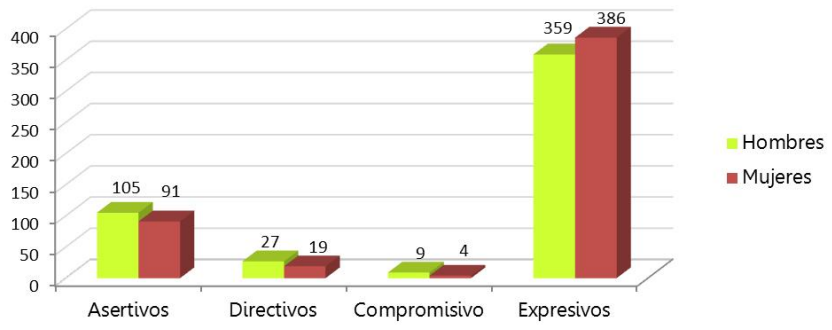

Fig. 7. Actos de habla.

La Figura 7 muestra que el acto de habla predominante es el expresivo, tanto en ellas como en ellos. El total de actos expresivos ha sido de 745 . De estos, 386 corresponden a mujeres (52\%), mientras que 359 , a hombres $(48 \%)$. Estos datos muestran que no existe una asimetría tan grande entre hombres y mujeres como algunos autores, citados anteriormente, consideran. En las redes sociales, todos expresan sus sentimientos, emociones y actitudes, ya sea directa o indirectamente, dirigidos a otras personas o no.

Otro acto de habla a considerar es el directivo. En la bibliografía especializada, se ha dicho que por cuestiones de cortesía las mujeres no establecen relaciones asimétricas con su interlocutor. Esto incluiría que no pueden dictar órdenes por encima de este. En nuestro caso, siguen siendo los hombres quienes emplean estos actos, pero a pesar de ello, la diferencia no es muy elevada. En los hombres, los actos directivos representarían un $59 \%$ del total de los 46 que se han analizado, mientras que en ellas, el porcentaje sería de $41 \%$.

\section{Cortesía}

Entendemos por cortesía el conjunto de estrategias conversacionales destinadas a evitar o mitigar las tensiones entre los interlocutores. Se considera un acto cortés aquel que demuestra cooperativismo, amabilidad y buena educación por parte del hablante. 
Lozano Domingo (1995), Lakoff (1995), Zernova (2000) y Penas (2009), entre otros autores, destacan la cortesía como un acto femenino. García Mouton (2003) considera que los principales comportamientos característicos de la cortesía femenina consistirían en sacar temas de conversación agradables, evitar los temas conflictivos, recurrir a la indirecta, evitar las palabras ofensivas, suavizar con los gestos y emplear cumplidos.

En nuestro caso, para establecer quiénes son más corteses, hombres o mujeres, nos centraremos en:

1. el uso de expresiones consideradas corteses socialmente;

2. en el empleo de oraciones indirectas;

3. en las tag questions, más conocidas como "preguntas coletilla", es decir, aquellas preguntas que aparecen al final de una frase para buscar la aprobación del interlocutor sobre lo que se ha dicho.

Cuando nos referimos a expresiones de cortesía, incluimos la lista de expresiones consideradas socialmente como "de buena educación". En este sentido, tendremos en cuenta interjecciones como gracias, enhorabuena o felicidades; expresiones desiderativas, del tipo buen día o feliz dia, y otras utilizadas para pedir un favor. El total de estas expresiones ha sido de 285, 150 en las 40 mujeres y 135 en 38 hombres.

En cambio, si tenemos en cuenta las ocasiones en las que se han empleado oraciones indirectas y tag questions obtenemos un resultado sorprendente: solo hemos encontrado 11 actos indirectos, 7 en mujeres y 4 en hombres, y 8 tag questions, 6 en mujeres y 2 en hombres (Figura 8).

Teniendo en cuenta estos datos, del total de 304 formas de cortesía, las mujeres han utilizado 163 (54\%), mientras que los hombres, 141 (46\%). Aunque la diferencia sea de un $8 \%$, los datos vuelven a coincidir con las estimaciones de la bibliografía. A pesar de ello, el porcentaje masculino es muy elevado. Este hecho da cuenta de que ha habido cambios importantes en cuanto a la estructura de la sociedad, puesto que, aunque todavía queda mucho por hacer, en los últimos treinta años la paridad entre hombres y mujeres se ha visto reforzada. De este modo, el estereotipo del hombre rudo y poco cortés se ha desligado de la hombría. Ahora las características que se consideran positivas en un hombre ya no difieren tanto de las que se consideran positivas en las mujeres y la cortesía es una actitud valorada en todos los seres humanos, sean estos hombres o mujeres. 


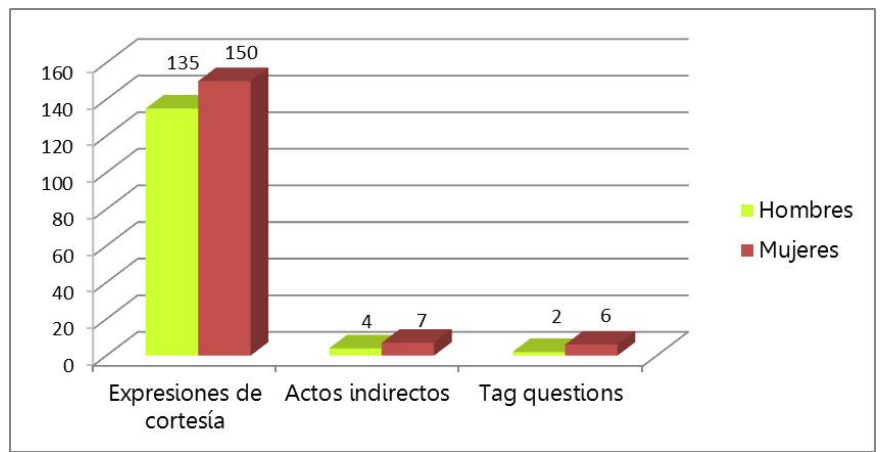

Fig. 8. Cortesía.

\section{Registro}

El registro que se utiliza en una conversación viene marcado por cuatro factores:

1. El medio de comunicación (oral o escrito);

2. El tema abordado;

3. Los participantes en la interacción;

4. La intención comunicativa.

Si tenemos en cuenta estos factores, el registro que predomina en nuestro corpus es el informal, manifestado a través del uso de la lengua coloquial y en algunos casos incluso vulgar. Solo existe un caso concreto que presenta un registro formal: el de la vicepresidenta del gobierno.

Respecto al registro, las conclusiones a las que llegamos son las siguientes:

- El medio de comunicación de nuestro corpus es la herramienta Twitter, por lo tanto, la comunicación se establece a través del medio escrito. A pesar de ello, los textos tienen la característica de estar oralizados, lo que hace plausible que se cree un contexto donde se utilice el registro informal/coloquial y no otro, ya que, como bien apunta Vigara (1992: 12): "El registro coloquial participa de todas las características de la lengua hablada y tiene definidas las suyas propias y diferenciadoras en virtud de su carácter conversacional". 
- Los temas abordados en los tuits que hemos analizado son diversos pero la mayoría de los sujetos se centran en hechos de su vida cotidiana y en su círculo más cercano, otro elemento que favorece el uso del registro informal.

- Los participantes en la comunicación a través de Twitter no están definidos como ocurre en una conversación tradicional, puesto que cuando el emisor escribe los tuits no sabe quiénes serán los receptores de estos. A pesar de ello, los sujetos que hemos analizado ejercen profesiones en las que es importante establecer lazos cooperativos con el público, lo que se solventa utilizando el registro informal, que resulta más cercano. Según Narbona:

El carácter marcadamente coloquial de una actuación lingüística deriva del hecho de que entre quienes hablan no haya distanciamientos de ninguna clase, que sea máxima la solidaridad, y nula o insignificante la disimetría de poder (relación superioridadinferioridad) entre ellos (Narbona 2015: 120).

- La intención comunicativa de los sujetos que hemos analizado es básicamente informativa y persuasiva, ya que tiene como objetivo comunicar próximos eventos relacionados con su persona o sentimientos propios. El lenguaje que utilizan es informal y coloquial, precisamente por la intención de estrechar lazos con el público que los sigue.

\subsection{Comunicación no Verbal: El Uso de los Emojis}

"La expresión comunicación no verbal alude a todos los signos y sistemas de signos no lingüísticos que comunican o se utilizan para comunicar" (Cestero Mancera 2006: 57). En toda conversación humana, la comunicación no verbal se combina con la verbal. De hecho, se considera que en la comunicación cara a cara el componente verbal es del $35 \%$ aproximadamente, frente al $65 \%$ que se corresponde con la comunicación no verbal. Como bien apunta Flora Davis (1976: 25): "las palabras son hermosas, fascinantes e importantes, pero las hemos sobreestimado en exceso, ya que no representan la totalidad, ni siquiera la mitad del mensaje".

El paralenguaje, la cinésica, la proxémica y la cronémica son los cuatro sistemas de comunicación no verbal que se tienen en cuenta. De ellos, los dos primeros, uno fónico y otro corporal, son considerados sistemas básicos o primarios por su implicación directa en cualquier acto de comunicación humana, ya que se ponen en funcionamiento a la vez que el sistema verbal para producir cualquier enunciado; los otros dos, el proxémico y el cronémico, son 
concebidos como sistemas secundarios o culturales, dado que actúan, generalmente, modificando o reforzando el significado de los elementos de los sistemas básicos o, independientemente, ofreciendo información social o cultural (Cestero Mancera 2006: 59).

Teniendo en cuenta esta clasificación, podemos elaborar la Tabla 2 con el fin de representar cuáles son los elementos que se tienen en cuenta a la hora de estudiar cada sistema dentro del acto de comunicación:

\begin{tabular}{|cccc|}
\hline \multicolumn{4}{c}{ COMUNICACIÓN NO VERBAL (CNV) } \\
\hline Paralenguaje & Cinésica & Proxémica & Cronémica \\
\hline Tono & Expresión facial & & \\
Ritmo & Mirada & Organización & Concepción, estructuración \\
Volumen & Postura & del espacio & y uso del tiempo \\
Silencios & Gestos & & \\
\hline
\end{tabular}

Tabla 2. Comunicación no verbal.

Existen una serie de características que son específicas de la comunicación mediada por ordenador y que hacen que la interacción y la comunicación sean distintas a las que se dan en la comunicación cara a cara. Siguiendo a Moral (2001), estas serían el anonimato, la ausencia de comunicación no verbal, el distanciamiento físico y el tiempo. La que nos interesa en este apartado es la referida a la comunicación no verbal.

¿Cómo podemos suplir la ausencia de comunicación no verbal en Twitter? A través de recursos expresivos y enfáticos que destaquen en el texto lo que en una conversación cara a cara codificaríamos de forma automática a través de expresiones no verbales.

Uno de los recursos más importantes y característicos a la hora de plasmar la comunicación no verbal en las redes sociales, además de los que afectan al paralenguaje, analizados escuetamente en el apartado de ortografía fonética, es el lenguaje de los emoticonos y emojis, que se utilizan para sustituir los elementos cinésicos como la expresión facial y los gestos.

En un primer momento, los emoticonos eran muy simples: se creaban por las combinaciones de caracteres del teclado con el fin de mostrar la expresión de una emoción en el rostro. Se utilizaban dos tipos básicos: para expresar actitudes positivas o negativas. Al ritmo de la evolución de las nuevas tecnologías, los emoticonos han ido ganando sofisticación en cuanto a la forma y 
al contenido semántico. Varias empresas telefónicas japonesas crearon una serie de emoticonos dibujados para facilitar su integración en diversos sistemas operativos telefónicos (Tascón 2002: 142). Los nuevos emoticonos no estaban elaborados con signos de puntuación combinados, sino que se representaban con solo pulsar una tecla, con lo cual su uso resultaba más cómodo que el de los tradicionales. Estos se conocieron como emojis, aunque el término emoticonos siguió y sigue utilizándose para nombrarlos.

Como muestra la Figura 9, los emojis utilizados en nuestro corpus han sido 942. De ellos, 252 han sido utilizados por hombres, mientras que 690, por mujeres. Un $48 \%$ de los emojis totales que se han utilizado pertenecen a categorías y campos semánticos muy diferentes: flora y fauna, astrología, meteorología, deportes, muestras de afecto y de amor y moda y belleza; aunque para nuestro análisis, nos interesan los emojis que se refieren a las expresiones corporales y faciales, puesto que son los que se relacionan con la comunicación no verbal. Estos representan un $20 \%$ y $32 \%$, respectivamente del total de emojis.
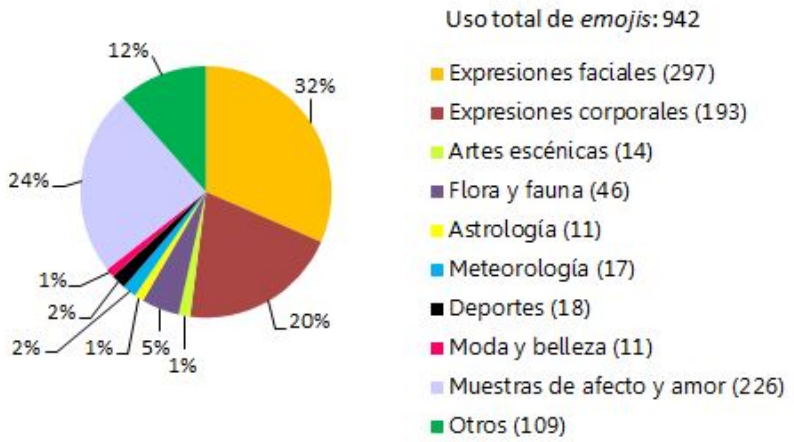

Fig. 9. Uso total de emojis.

Paul Ekman et al. (1972) en sus estudios psicológicos acerca de las emociones, demostraron que los gestos faciales eran un fiel reflejo de estas y clasificaron dichas expresiones según la emoción que denotaban en siete grandes grupos: felicidad, tristeza, ira, asco, sorpresa, miedo y desprecio. Más tarde, Ekman (1999) amplió esta lista de emociones incluyendo otras que no tenían una correlación tan clara con la expresión del rostro: alivio, bochorno, compla- 
cencia o contento, culpa, diversión, entusiasmo o excitación, orgullo o soberbia, satisfacción, sorpresa y vergüenza.

Para elaborar nuestro análisis nos hemos basado en algunos elementos de esta clasificación, aunque también hemos añadido otros más que se adecuaban al sentido del gran número de emojis faciales y corporales diferentes que hemos hallado: placer, adoración, desconsolación, guiño o reflexión, beso, beso amoroso, motivación, aprobación, perfección, admiración, rebeldía, triunfo, deseo, saludo, fuerza, alegría intensa y picardía.

De un total de 40 hombres, 23 utilizan emojis faciales y corporales, mientras que del total de 40 mujeres, 32 los utilizan. Estos datos representan un $57 \%$ frente a un $80 \%$, con lo cual una vez más, se confirman las teorías que encontramos en la bibliografía. Como bien apuntan López García y Morant (1995: 86): "la mayor expresividad facial y corporal corresponde al sexo femenino". Las mujeres son más expresivas que los hombres y utilizan un "lenguaje emocional" que en Twitter se exterioriza a través de estos recursos expresivos.

Teniendo en cuenta estos datos, la frecuencia de uso de los emojis faciales es mayor en mujeres que en hombres. En ellas representa un $64 \%$ frente al $36 \%$ de ellos, partiendo de un total de 297 ocasiones en las que han aparecido. En el caso de las corporales, la diferencia no es tan significativa ( $46 \%$ en mujeres frente al $54 \%$ en hombres, de las 193 ocasiones en las que han aparecido).

Centrándonos solo en los emojis faciales y corporales, en los que la diferencia de uso entre hombres y mujeres es más significativa, podemos afirmar que:

- Los emojis que presentan más diferenciación son los que se utilizan para denotar diversión, adoración, desconsolación, motivación, aprobación, alegría intensa y el utilizado para enviar un beso amoroso.

- De esta clasificación, podemos considerar que los emojis referentes a $d i$ versión y a aprobación son más neutrales que los demás, puesto que son términos que no presentan gradación semántica hacia ningún extremo.

- A diferencia de los anteriores, la adoración, desconsolación, la alegría intensa y el beso amoroso son términos que expresan un extremo máximo de gradación semántica.

- Los emojis referentes a diversión y a aprobación son utilizados más a menudo en los hombres que en las mujeres. 
- Los emojis referentes a adoración, desconsolación, alegría intensa y beso amoroso aparecen en las mujeres con mayor frecuencia que en los hombres. Una vez más, obtenemos un resultado que corrobora los datos bibliográficos: las mujeres son más expresivas y además de forma más intensa que los hombres cuando se trata de expresar sentimientos y emociones.

Para finalizar, podemos destacar que la variable edad, además de la de sexo, es la que más influye en estos rasgos. Los jóvenes son quienes más utilizan los emojis. Conforme vamos avanzando en la escala de edad, estos disminuyen e incluso desaparecen, sobre todo en el caso de los hombres.

\section{Conclusiones}

En la bibliografía especializada, se ha considerado el habla de la mujer como emocional, expresiva, normativa, conservadora, cortés, educada e insegura. Por el contrario, son pocos los libros o artículos en los que aparece una descripción tan detallada del generolecto masculino. Se entiende que los hombres utilizan el lenguaje por oposición a las mujeres, sin detallarse unas características tan explícitas como se hace en el caso femenino. De esta manera, el lenguaje masculino se considera lógico, poco expresivo, relacionado con las variedades vernáculas, innovador, poco cortés, agresivo y grotesco.

Durante mucho tiempo, el papel de las mujeres estaba relegado a la familia y el hogar y el de los hombres, al ámbito social y laboral. En este sentido, no es de extrañar que, en una sociedad anclada en valores tradicionales, se creasen estos estereotipos del lenguaje de unos y otros.

Actualmente, esta situación ha cambiado. Cuando se produce un cambio en la sociedad también lo hace en el lenguaje de los grupos que la forman, por lo tanto, los estereotipos tradicionales no se corresponden del todo con la realidad actual. En consecuencia, pensamos que se deberían actualizar en algunos aspectos.

Para proporcionar los rasgos que se deben tener en cuenta a la hora de formalizar una caracterización generolectal adaptada a la realidad actual, tendremos en cuenta aquellos elementos de los diferentes niveles lingüísticos en los que destaquen los hombres o las mujeres en cuanto al número de sujetos que los utilicen y no en cuanto a la frecuencia de uso. 
Partiendo del total de 40 hombres y 40 mujeres que se han analizado podemos afirmar que la identidad de hombres o mujeres se podrá detectar teniendo en cuenta los rasgos especificados en la Tabla 3.

\begin{tabular}{|c|c|c|}
\hline $\begin{array}{l}\text { CATEGORIAS } \\
\text { GRAMATICALES }\end{array}$ & MUJERES & HOMBRES \\
\hline $\begin{array}{l}\text { Ortografia } \\
\text { fonética }\end{array}$ & $\begin{array}{l}\text { - Uso de ortografía coloquial } \\
\text { - Alargamiento de vocales y } \\
\text { consonantes con valor expresivo } \\
\text { para representar cualidades } \\
\text { prosódicas como la duración } \\
\text { - Uso de partículas exclamativas }\end{array}$ & $\begin{array}{l}\text { - Uso de mayúsculas para } \\
\text { representar cualidades } \\
\text { prosódicas como la intensidad } \\
\text { vocal }\end{array}$ \\
\hline Morfología & - Uso de prefijos intensificadores & $\begin{array}{l}\text { - Uso de sufijos aumentativos y } \\
\text { despectivos }\end{array}$ \\
\hline Léxico & - & $\begin{array}{l}\text { - Uso de palabras malsonantes e } \\
\text { insultos }\end{array}$ \\
\hline $\begin{array}{l}\text { Comunicación } \\
\text { no verbal }\end{array}$ & $\begin{array}{l}\text { - Uso de emoijs, especialmente } \\
\text { corporales y faciales y referidos a } \\
\text { muestras de afecto }\end{array}$ & 一 \\
\hline
\end{tabular}

Tabla 3. Identidad hombres/mujeres: Rasgos.

En los rasgos referidos a ortografía homofónica, sufijos diminutivos, acortamientos, extranjerismos, interjecciones y onomatopeyas, adjetivos calificativos y expresiones y fórmulas de cortesía, parece ser que no existen apenas diferencias entre hombres y mujeres, por lo que no son importantes si se busca establecer esta diferenciación.

El hecho de que existan rasgos en los que hombres y mujeres no muestren diferencias significativas se debe a que, al contrario de lo que se manifiesta en la bibliografía tradicional, actualmente los hombres son tan expresivos y corteses como las mujeres, puesto que no difieren de ellas en el uso de sufijos diminutivos, interjecciones y onomatopeyas, adjetivos calificativos $\mathrm{y}$ expresiones y fórmulas de cortesía.

Ellas tampoco son tan conservadoras, normativas e inseguras, ya que utilizan extranjerismos, ortografía homofónica y pocas tag questions.

Con el análisis que se presenta en este estudio nos gustaría dejar claro que ninguno de los dos generolectos es mejor ni superior al otro, sino que cada uno se adecúa a los propósitos que cada persona tiene a la hora de comunicarse. Que seamos conscientes de que existen divergencias en el lenguaje entre hombres y mujeres no debe ser algo que nos lleve a valorar de forma diferente 
a unos y otros, estableciendo roles de superioridad en ellos y de inferioridad en ellas como la tradición ha marcado, sino que debería ser un aspecto que fomentara el conocimiento mutuo de los dos géneros y que contribuyese a la mejor comunicación entre las personas.

Tras haber realizado este estudio, podemos insistir en que las tareas de detección automática de género no se pueden basar en la proporción de elementos utilizados en hombres y mujeres teniendo en cuenta las categorías gramaticales, puesto que un análisis de este tipo no proporciona toda la fiabilidad que se busca en estas tareas, como muestran las Figuras 10, 11 y 12.

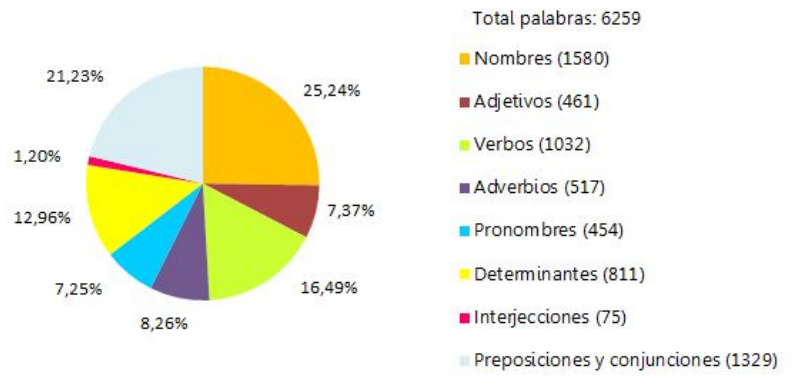

Fig. 10. Mujeres: Número y porcentaje de categorías gramaticales analizadas.

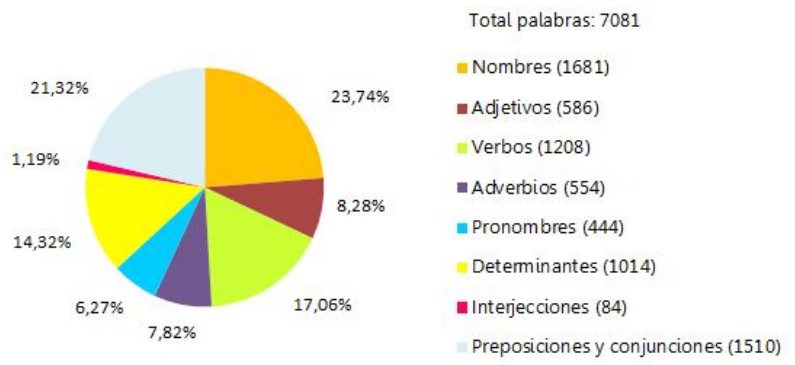

Fig. 11. Hombres: Número y porcentaje de categorías gramaticales analizadas. 


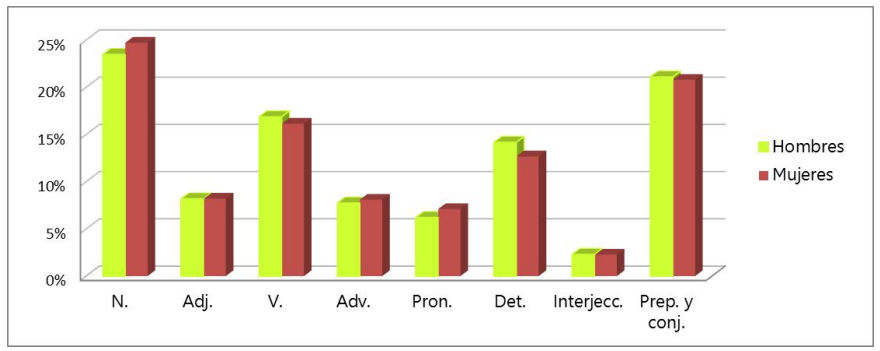

Fig. 12. Categorías gramaticales analizadas: Comparativa Hombres y Mujeres.

En este sentido, se precisa la participación de expertos en el lenguaje para que analicen otros datos que sean verdaderamente significativos teniendo en cuenta la diferenciación generolectal. Las labores de los sociolingüistas y los lingüistas son indispensables para obtener un buen análisis, basado en el contenido de los mensajes más que en la forma.

\section{Bibliografía}

1. Aguirre, C. (2013). Manual de morfología. Barcelona: Castalia Ediciones.

2. Alemán, Y.; Vilariño, D. \& Pinto, D (2014). Una metodología para la detección del perfil de un autor. Research in computing Science, 85: 93-103.

3. Almela, R. (1999). Procedimientos de formación de palabras en español. Barcelona: Ariel.

4. Araujo, M. H. \& Melo, S. (2006). Del caos a la creatividad: los chats entre lingüistas y didactas. Estudios de Lingüistica del Español, 24.

5. Austin, J. L. (1962). Cómo hacer cosas con palabras. Barcelona: Paidós.

6. Burger, J. D.; Henderson, J.; Kim, G. \& Zarrella, G. (2011). Discriminating gender on Twitter. In Proceedings of the Conference on Empirical Methods in Natural Language Processing (pp. 1301-1309). Association for Computational Linguistics.

7. Calero Fernández, M.Á. (2007). Percepción social de los sociolectos. Cádiz: Servicio de Publicaciones Universidad de Cádiz.

8. Cestero Mancera, A. M. (2006). La comunicación no verbal y el estudio de su incidencia en fenómenos discursivos como la ironía. ELUA.Estudios de Lingüistica, 20: 57-77.

9. Chambers, J.K. (1994). Sociolinguistic theory: linguistic variation and its social significance. Oxford: Basil Blackwell.

10. Cheng, N.; Chandramouli, R. \& Subbalakshmi, K. P. (2011). Author gender identification from text. Digital Investigation, 8(1): 78-88. 
11. Coates, J. (1989). Women in their speech communities: New perspectives on language and sex. London-New York: Longman.

12. Coates, J. (2003): Men talk: Stories in the making of masculinities. Oxford: Blackwell Publishing.

13. Company, C. (2003). Normatividad y cambio lingüistico. México: Universidad Nacional Autónoma de México.

14. Crystal, D. (2002). El lenguaje e internet. Madrid: Cambridge University Press.

15. Di Tullio, A. (2010). Manual de gramática del español. Argentina: Waldhuter Editores.

16. Ekman, P. (1999). Basic Emotions. In Dalgleish, T. \& Power, M. J. (eds.), Handbook of Cognition and Emotion. New York: John Wiley \& Sons Ltd.

17. Ekman, P.; Friesen, W.V. \& Ellsworth, P. (1972). Emotion in the human face: Guidelines for Research and an integration of findings. New York: Pergamon Press.

18. Davis, F. (1976). La comunicación no verbal. Madrid: Alianza Editorial.

19. García Mouton, P. (2003). Así hablan las mujeres; curiosidades y tópicos del uso femenino del lenguaje. Madrid: La Esfera de los Libros.

20. Jespersen, O. (2007). Language. It's nature and origin. Oxon: Routledge.

21. Koppel, M.; Argamon, S. \& Shimoni, A. R. (2002). Automatically Categorizing Written Texts by Author Gender. Literary $\&$ Linguistic Computing, 17(4): 401412.

22. Labov, W. (1966). The social stratification of English in New York City. Washington: Center for Applied Linguistics.

23. Labov, W. (1972a). Sociolingüistic patterns. Philadelphia: University of Pensilvania Press.

24. Labov, W. (1972b). Language in the inner city: studies in the Black English vernacular. Philadelphia: University of Pensilvania Press.

25. Lakoff, R. (1995). El lenguaje y el lugar de la mujer. Barcelona: Hacer.

26. Lang, M.F (1992). Formación de palabras en español: morfología derivativa productiva en el léxico moderno. Madrid: Cátedra.

27. Llisterri, J. (2002). Marcas fonéticas de la oralidad en la lengua de los Chats: Elisiones y epéntesis consonánticas. Revista de investigación lingüistica, 2: 61100.

28. López García, A \& Morant, R. (1995). Gramática femenina. Madrid: Cátedra.

29. Lozano Domingo, I. (1995). Lenguaje femenino, lenguaje masculino, ¿Condiciona nuestro sexo la forma de hablar? Madrid: Minerva Ediciones.

30. Moral, F. (2001). Aspectos psicosociales de la comunicación y de las relaciones personales en Internet. Anuario de Psicología, 2: 13-30.

31. Moreno Fernández, F. (1998). Principios de sociolingüistica y sociología del lenguaje. Barcelona: Ariel.

32. Narbona Jiménez, A. (2015). Sintaxis del español coloquial. Sevilla: Universidad de Sevilla. 
33. Penas Ibáñez, M.A. (2009). Semántica del discurso: la variable género. Una investigación sobre el sexismo semántico. Revista electrónica Linred, Lingüistica en la Red.

34. Queralt, S. (2014). Acerca de la prueba lingüística en atribución de autoría hoy. Revista de Llengua i Dret, 62: 35-48.

35. Real Academia Española (2009). Nueva gramática de la lengua española: Morfología y sintaxis I. Madrid: Espasa-Calpe.

36. Schler, J.; Koppel, M.; Argamon, S. \& Pennebaker, J. W. (2006). Effects of Age and Gender on Blogging. In AAAI Spring Symposium: Computational Approaches to Analyzing Weblogs, 6: 199-205.

37. Silva-Corvalán, C. (2001). Sociolingüistica y pragmática del español. Washington: Georgetown University Press.

38. Searle, J. (1969). Actos de habla: ensayo de filosofía del lenguaje. Madrid: Cátedra, 1980.

39. Spencer-Oatey, H. (2008). Culturally speaking. Culture, Communication and Politeness Theory. London: Continuum.

40. Tascón, M. (2012). Escribir en Internet: guía para los nuevos medios y las redes sociales. Fundéu BBVA. Barcelona: Galaxia Gutenberg.

41. Turell Julià, M.T. (1995). La sociolingüistica de la variación. Barcelona: Promociones y publicaciones universitarias.

42. Vigara, A.M. (1992). Morfosintaxis del español coloquial: esbozo estilístico. Madrid: Gredos.

43. Yus, F. (2010). Ciberpragmática 2.0: Nuevos usos del lenguaje en internet. Barcelona: Planeta.

44. Zernova, Y. (2000). Algunos factores diferenciadores del habla masculina y femenina. In Actas de la II Conferencias de Hispanistas de Rusia. Madrid.

\section{Author's Biodata}

Clàudia Giménez Bedós es graduada en Lengua y Literatura Hispánicas por la Universitat Rovira i Virgili. Sus intereses están centrados en las relaciones entre la lengua y la sociedad, especialmente en las que interviene la variable social del sexo/género, y en los ámbitos de estudio propios de la lingüística forense. 